\title{
A Review of TiNiPdCu Alloy System for High Temperature Shape Memory Applications
}

\author{
M. Imran Khan ${ }^{1,2} \cdot$ Hee Young $\operatorname{Kim}^{1} \cdot$ Shuichi Miyazaki ${ }^{1,2,3}$
}

Published online: 17 June 2015

(C) ASM International 2015

\begin{abstract}
High temperature shape memory alloys (HTSMAs) are important smart materials and possess a significant potential to improve many engineering systems. Many TiNi-based high temperature ternary alloy systems have been reported in literature including TiNiPd, TiNiPt, TiNiZr, TiNiAu, TiNiHf, etc. Some quaternary additions of certain elements in the above systems have been successful to further improve many important shape memory and mechanical properties. The success criteria for an HTSMA become strict in terms of its cyclic stability, maximum recoverable strain, creep resistance, and corrosion resistance at high temperatures. TiNiPdCu alloy system has been recently proposed as a promising HTSMA. Unique nanoscaled precipitates formed in TiNiPdCu-based HTSMAs are found to be stable at temperatures above $773 \mathrm{~K}$, while keeping the benefits of ease of fabrication. It is expected that this alloy system possesses significant potential especially for the high temperature shape memory applications. Till now many research reports have been published on this alloy system. In the present work, a comprehensive review of the TiNiPdCu system is presented in terms of thermomechanical behavior, nanoscale
\end{abstract}

Hee Young Kim

heeykim@ims.tsukuba.ac.jp

Shuichi Miyazaki

miyazaki@ims.tsukuba.ac.jp

1 Division of Materials Science, University of Tsukuba, Tsukuba, Ibaraki 305-8573, Japan

2 Faculty of Materials Science and Engineering, GIK Institute of Engineering Sciences and Technology, Topi, KPK, Pakistan

3 Foundation for Advancement of International Science, Tsukuba, Ibaraki 305-0821, Japan precipitation mechanism, microstructural features, high temperature shape memory and mechanical properties, and the important parameters to control the high temperature performance of these alloys.

Keywords TiNiPdCu-based alloys $\cdot$ High temperature shape memory effect $\cdot$ Nanoscale precipitation · Cold deformation $\cdot$ Annealing $\cdot$ Aging $\cdot$ Martensitic transformation

\section{Introduction}

High temperature shape memory alloys (HTSMAs) are those shape memory alloys which possess higher martensitic transformation temperatures at least exceeding $373 \mathrm{~K}$. Recently, a significant research focus has been observed in the area of high temperature shape memory actuators mainly for space exploration applications, power generation, and automotive applications [1-5]. Many potential applications of high temperature shape memory alloys for aircraft and space applications have been proposed in literature i.e., high temperature solid state actuators, adaptive chevron attached at core exhausts for noise control and fuel efficiency in aircrafts, variable area or variable geometry inlets, high force actuation systems, actuators for deployment of space structures in satellites, deployable shields and protection screens, seals for booster ring segments of rockets, and release mechanisms for rocket launching [6-10]. Many potential uses of HTSMAs have also been proposed for various automobile applications especially for engine control and fuel management purposes [11]. Another potential area of HTSMAs usage is energy exploration for downhole oil and gas applications such as flow safety valves, control valves, and compact actuators [12, 13]. High temperature 
shape memory alloys also have potential uses in the area of MEMS i.e., microvalves with better response time as compared to that of binary TiNi alloy-based microvalves [14]. Orbital Research, Inc. has recently developed a strain gage for a pressure transducer, using HTSMA thin films which uses the superelastic properties of HTSMAs [15]. These are the only few potential applications of HTSMAs and surely there are still many areas which are still to be explored for the potential applications of HTSMAs. Still the HTSMAs are not in the market to be used for real-time commercial applications mainly because of the lack of adequate cold workability and poor high temperature functional properties [16]. Binary TiNi shape memory alloys are not suitable for high temperature applications [17]. Some TiNi-based ternary alloys such as TiNiPt, TiNiAu, TiNiZr, TiNiPd, and TiNiHf have shown suitable transformation temperatures for the above-mentioned applications [18-21]. Small hysteresis is an essential requirement for actuator-type applications. TiNiPd, TiNiPt, and TiNiAu alloys exhibit high temperature shape memory effect and also possess small hysterisis. A detailed review on the above-mentioned HTSMAs can be found in a review paper by Ma et al. [5]. In these alloys the transformation temperatures can be controlled by changing the concentration of ternary alloying elements within a temperature range of $373-773 \mathrm{~K}$. A negative aspect of these alloys is their relatively higher cost as compared to that of other HTSMAs [18, 22]. The relatively less costly TiNiHf and TiNiZr alloys also exhibit high transformation temperatures but their thermal hysterisis is much larger $(\approx 45 \mathrm{~K})$ which makes them unsuitable for the actuator type of applications. Moreover the TiNiHf- and TiNiZr-based alloys both possess very poor cold workability and it is almost impossible to apply the conventional strengthening techniques i.e., by precipitation strengthening, strain hardening, etc., in order to improve their high temperature stability [23-25]. In TiNiPd-based ternary high temperature shape memory alloys offer an attractive combination of high transformation temperatures, small hysterisis, adequate workability, and a relatively less cost compared to that of other TiNi-based ternary high temperature shape memory alloy systems [26-30].

Like any other metallic materials, the high temperature functional performance of TiNiPd-based alloys is severely compromised mainly because of creep deformation and transformation-induced plasticity [31-33]. Our group has recently proposed $\mathrm{TiNiPdCu}$-based high temperature system especially for high temperature shape memory effect applications [33, 34]. These alloys were found to exhibit an exceptional behavior regarding their high temperature cyclic stability and creep properties especially in harsh working conditions because of a unique nanoscale precipitation behavior. Also because of this unique precipitation behavior involving lattice defects formed during cold working now the precipitation strengthening mechanism is possible to be applied in TiNiPd-based HTSMAs which is normally not possible in HTSMAs due to their inherited poor cold workability $[34,35]$. Till now many research reports regarding various important aspects of $\mathrm{TNiPdCu}$ alloy system have been published. The purpose of this review paper is to present a collective overview of all the important aspects of TiNiPdCu alloy system which have been explored till now.

\section{Effect of $\mathrm{Cu}$ Addition on the Mechanical and Shape Memory Properties of TiNiPd-Based Alloys}

Lin et al. studied the effects of $\mathrm{Cu}$ addition on the characteristics of various $\mathrm{Ti}_{50} \mathrm{Ni}_{25-X} \mathrm{Pd}_{25-Y} \mathrm{Cu}_{X+Y}$ alloys by either substituting $\mathrm{Ni}$ or $\mathrm{Pd}$ by $\mathrm{Cu}$. The substitution of $\mathrm{Ni}$ by $\mathrm{Cu}$ increases the values of transformation temperature while that of $\mathrm{Pd}$ by $\mathrm{Cu}$ shows a reverse effect. Their results show that all the TiNiPdCu-based alloys exhibit a B2-B19 martensitic transformation sequence with $M_{\mathrm{s}}$ temperatures in the range of 330-453 K. This study also points out that the $\mathrm{Cu}$ addition affects the lattice constants of B19 martensite and the effect of Pd substituted by $\mathrm{Cu}$ on the lattice constants of B19 martensite is more significant than that of $\mathrm{Ni}$ by $\mathrm{Cu}$. The study claims that substitution of $\mathrm{Ni}$ by $\mathrm{Cu}$ can decrease the lattice parameter "a" but increase "b" and "c"; while that of $\mathrm{Pd}$ by $\mathrm{Cu}$ shows a reverse behavior. This observation was attributed to the different atomic radii of $\mathrm{Ni}, \mathrm{Cu}$, and $\mathrm{Pd}$ (the atomic radius of $\mathrm{Ni}$ is smaller than that of $\mathrm{Cu}$ and that of Pd is larger than that of $\mathrm{Cu}$ ). The study also shows that the substitution of $\mathrm{Ni}$ and $\mathrm{Pd}$ by $\mathrm{Cu}$ increases the hardness and decreases the cold rolling workability which is attributed to the solid solution strengthening effect of $\mathrm{Cu}$. Based on the stress-free thermal cycling test, within the temperature range of 323 and $573 \mathrm{~K}$ for 100 times, the study also shows that the $\mathrm{Ti}_{50} \mathrm{Ni}_{15} \mathrm{Pd}_{25}$ $\mathrm{Cu}_{10}$ alloy exhibits good thermal stability [36].

Our research group has recently reported that addition of $\mathrm{Cu}$ in TiNiPd system shows some beneficial effect on the mechanical and shape memory characteristics mainly because of solid solution strengthening mechanism [33]. Three alloys were prepared by conventional Ar-arc melting method and were solution treated at $1173 \mathrm{~K}$ for $3.6 \mathrm{ks}$ in an inert atmosphere followed by subsequent quenching in water. Hereafter, the alloys are referred according to their $\mathrm{Cu}$ contents (at.\%), i.e., $0 \mathrm{Cu}, 5 \mathrm{Cu}$, and $10 \mathrm{Cu}$. The DSC results confirm that addition of $\mathrm{Cu}$ slightly increases the martensitic transformation temperatures while the thermal hysterisis remains almost constant $(\approx 13 \mathrm{~K})$. Microstructural investigation tells that $\mathrm{Cu}$ addition does not promote the formation of any 2 nd phase precipitates. Also the $\mathrm{Cu}$ addition has no obvious effect on grain size and on the 
morphology of the B19 martensite. Cu addition increases the lattice parameters of orthorhombic B19 martensite as shown in XRD results given in Fig. 1. A consistent shift in the XRD pattern suggests that the $\mathrm{Cu}$ addition in TiNiPd alloys affects the lattice parameters mainly because of the relatively larger atomic radius of $\mathrm{Cu}(0.128 \mathrm{~nm})$ as compared to that of $\mathrm{Ni}(0.125 \mathrm{~nm})$. Table 1 shows the calculated lattice parameters of TiNiPd and TiNiPdCu alloys. $\mathrm{Cu}$ addition has beneficial effects on shape recovery strain, plastic strain levels, and resistance against creep deformation especially at high stress and high temperature levels as evidenced by constant stress thermal cycling test results shown in Fig. 2. It is expected that the improved high temperature shape memory characteristics of TiNiPdCu alloys are because of solid solution strengthening effect of $\mathrm{Cu}$ [33]. Another study has also recently reported that the addition of 5 at. $\% \mathrm{Cu}$ in a $\mathrm{Ti}_{50} \mathrm{Ni}_{25} \mathrm{Pd}_{25}$ alloy, replacing $\mathrm{Ni}$, increases the fracture stress of martensite phase and stress required for the reorientation of martensite variants by 33 and $60 \mathrm{MPa}$, respectively along with a $0.75 \%$ decrease in the strain to fracture, mainly due to the solid solution strengthening effect of $\mathrm{Cu}$. Also the critical stress for slip and fracture stress of the austenite phase both are increased by 62 and $41 \mathrm{MPa}$, respectively along with a $1.2 \%$ decrease in the strain to fracture. The same study also claims that $\mathrm{Ti}_{50} \mathrm{Ni}_{25} \mathrm{Pd}_{25}$ and $\mathrm{Ti}_{50} \mathrm{Ni}_{20} \mathrm{Pd}_{25} \mathrm{Cu}_{5}$, both the alloys, exhibit partial pseudoelasticity and because of $\mathrm{Cu}$ addition, the stress hysteresis is reduced as well as stabilized [37].

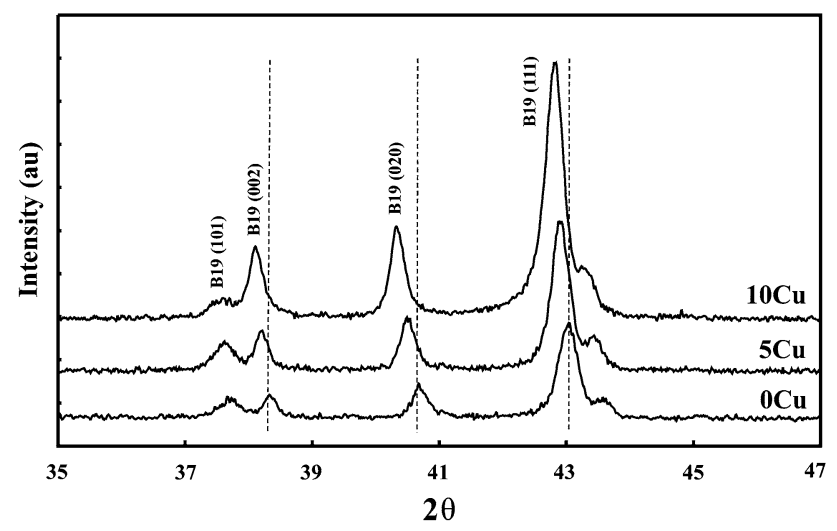

Fig. $1 \mathrm{XRD}$ profiles obtained at $298 \mathrm{~K}$ for $0 \mathrm{Cu}, 5 \mathrm{Cu}$, and $10 \mathrm{Cu}$ alloys [33]

Table 1 Lattice parameters of B19 martensite phase and mechanical properties of $0 \mathrm{Cu}, 5 \mathrm{Cu}$, and $10 \mathrm{Cu}$ alloys [33]

\begin{tabular}{lllllll}
\hline Alloy & $a(\mathrm{~nm})$ & $b(\mathrm{~nm})$ & $c(\mathrm{~nm})$ & $\sigma_{\mathrm{y}}(\mathrm{MPa})$ & $\sigma_{\mathrm{f}}(\mathrm{MPa})$ & $\varepsilon_{\mathrm{f}}(\%)$ \\
\hline $0 \mathrm{Cu}$ & 0.2794 & 0.4362 & 0.4620 & 805 & 1005 & 12.5 \\
$5 \mathrm{Cu}$ & 0.2801 & 0.4365 & 0.4642 & 827 & 1047 & 13.3 \\
$10 \mathrm{Cu}$ & 0.2811 & 0.4379 & 0.4668 & 850 & 1090 & 12.9 \\
\hline
\end{tabular}

\section{Defect-Assisted Nanoscale Precipitation Behavior in $\mathbf{T i}_{50} \mathrm{Ni}_{15} \mathbf{P d}_{25} \mathrm{Cu}_{10}$ Alloy}

Our group has recently reported a unique nanoscale precipitation behavior in a thermomechanically treated $\mathrm{Ti}_{50}$ $\mathrm{Ni}_{15} \mathrm{Pd}_{25} \mathrm{Cu}_{10}$ alloy [34]. Solution-treated $\mathrm{Ti}_{50} \mathrm{Ni}_{25} \mathrm{Pd}_{25}$ and $\mathrm{Ti}_{50} \mathrm{Ni}_{15} \mathrm{Pd}_{25} \mathrm{Cu}_{10}$ alloys were first cold rolled up to $40 \%$ and then subsequently annealed at different temperatures within a temperature range of 623-973 K. Hereafter, the alloys are referred according to their $\mathrm{Cu}$ contents (at.\%), i.e., $0 \mathrm{Cu}$ and $10 \mathrm{Cu}$. DSC results of the thermomechanically treated (cold deformed + annealed) alloys reveal a unique shape memory behavior in case of $10 \mathrm{Cu}$ alloy. The $10 \mathrm{Cu}$ alloy shows a severe depression in martensitic transformation temperatures upon annealing within a temperature range of $623-923 \mathrm{~K}$ as compared to that of $0 \mathrm{Cu}$ alloy. Similarly the XRD results of the annealed $10 \mathrm{Cu}$ alloy show significantly different XRD patterns as compared to that of $0 \mathrm{Cu}$ alloy as shown in Fig. 3. The annealing treatment of ternary $\mathrm{OCu}$ alloy results in an expected evolution of orthorhombic B19 martensite peaks with the annealing temperature mainly because of recovery and recrystallization processes. In case of annealed $10 \mathrm{Cu}$ alloy, formation of $\mathrm{B} 2$ parent phase, a Ti-rich $\mathrm{Ti}_{2} \mathrm{Pd}$ phase, and a $\mathrm{Cu}$-rich $\mathrm{TiPdCu}$ phase can be noticed. The significant depression in martensitic transformation temperatures is attributed to the formation of two types of fine precipitates. The abovementioned XRD results can also be confirmed by backscattered-SEM images as shown in Fig. 4 [34]. Although the XRD results indicate a very strong presence of Ti-rich $\mathrm{Ti}_{2} \mathrm{Pd}$-type precipitates and $\mathrm{Cu}$-rich $\mathrm{TiPdCu}$ precipitates in case of $723 \mathrm{~K}$ and $773 \mathrm{~K}$ annealed $\mathrm{Ti}_{50}$ $\mathrm{Ni}_{15} \mathrm{Pd}_{25} \mathrm{Cu}_{10}$ alloy but the backscattered-SEM images of these samples do not reveal their presence because of their very fine size. TEM analysis of $773 \mathrm{~K}$ annealed $10 \mathrm{Cu}$ alloy confirms their presence as shown in Fig. 5a-d [34]. The BF-TEM image of solution-treated 10Cu alloy shows that the addition of $\mathrm{Cu}$ in $\mathrm{Ti}_{50} \mathrm{Ni}_{25} \mathrm{Pd}_{25}$ alloy does not change the morphology of orthorhombic B19 martensite that is commonly found in TiNiPd-based alloys. The SAD pattern shown in Fig. 5a confirms the presence of $\{111\}$ type-I twins in the solution-treated $10 \mathrm{Cu}$ alloy which is, according to the previous literature, mostly found as twinning mode in TiNiPd-based alloys [34, 38-40].

The SEM results also reveal that as the annealing temperature increases the precipitates become coarser and their density decreases. At $973 \mathrm{~K}$ annealing temperature, a low density of only the coarse white precipitates can be seen in Fig. 4f [34]. This is because of the fact that at that high annealing temperature the weaker heterogeneous nucleation sites are eliminated before the formation of stable nuclei of TiPdCu-type precipitates and nucleation is only 
Fig. 2 Strain-temperature curves of $\mathbf{a} 0 \mathrm{Cu}, \mathbf{b} 5 \mathrm{Cu}$, and c $10 \mathrm{Cu}$ alloys under various stresses and $\mathbf{d}$ measurement scheme of shape memory characteristics on straintemperature curves [33]
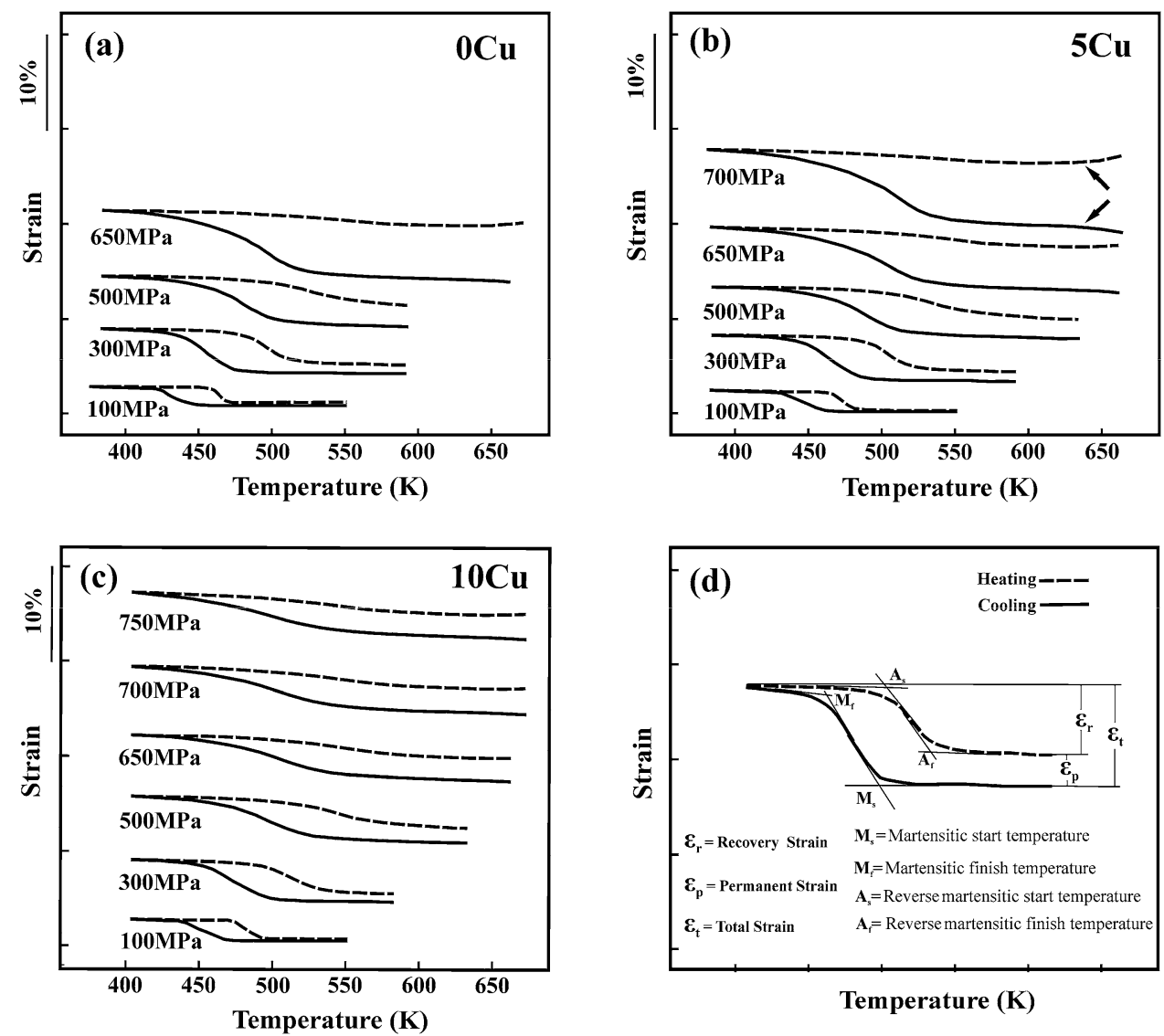

Temperature (K) possible on the most stable heterogeneous nucleation sites. The X-ray mapping and EPMA spot chemical analysis results reveal that the black precipitates are Ti-rich $\mathrm{Ti}_{2} \mathrm{Pd}$ type precipitates and white precipitates are TiPdCu-type precipitates as shown in Fig. 6 and Table 2 [34].

\section{Precipitation Mechanism in Annealed TiNiPdCu Alloys}

Many research reports have indicated the preferential precipitation of $\mathrm{Cu}$-rich precipitates at the open volume defects in many alloy systems, including $\mathrm{Fe}-\mathrm{Cu}$ and $\mathrm{Fe}-\mathrm{Cu}-\mathrm{B}-\mathrm{N}$ alloys [41]. Semboshi et al. reported the formation of $\mathrm{Cu}$-rich $\mathrm{Cu}_{4} \mathrm{Ti}$ and $\mathrm{TiH}_{2}$ precipitates, which were preferentially formed at lattice defects, i.e., dislocations and nanosized deformation twins in a deformed and subsequently aged $\mathrm{Cu}-4.2 \mathrm{~mol} \% \mathrm{Ti}$ alloy [42]. Lin et al. reported the formation of $\mathrm{Ti}(\mathrm{Cu}, \mathrm{Ni})_{2}$ precipitates on the defects in a $30 \%$ cold deformed and subsequently annealed $\mathrm{Ti}_{50} \mathrm{Ni}_{40} \mathrm{Cu}_{10}$ alloy [43]. In $\mathrm{Ti}_{50} \mathrm{Ni}_{15} \mathrm{Pd}_{25} \mathrm{Cu}_{10}$ alloy, $\mathrm{Cu}$ acts in a similar way and tries to form $\mathrm{Cu}$-rich $\mathrm{TiPdCu}$-type precipitates at the heterogeneous nucleation sites provided by the deformationinduced and other type of defects [34]. This fact can be confirmed from the XRD scans of solution-treated $0 \mathrm{Cu}$ alloy,
$10 \mathrm{Cu}$ alloy annealed at $973 \mathrm{~K}$, and solution-treated $10 \mathrm{Cu}$ alloy. In the previous section it was shown that addition of $\mathrm{Cu}$ in TiNiPd alloys increases the lattice parameter of orthorhombic B19 martensite. When the TiNiPdCu alloy is cold deformed and subsequently annealed at $773 \mathrm{~K}$ for $3.6 \mathrm{ks}$, TiPdCu precipitates are formed due to the preferential diffusion of $\mathrm{Cu}$ toward the deformation-induced defects and as a result the XRD peaks shift back indicating a decrease in lattice parameters of orthorhombic B19 martensite [34]. This observation verifies and strengthens the above-mentioned argument. The combined formation of Tirich and Ti-lean precipitates in TiNiPdCu alloys is because of a spinodal decomposition-type process. A possible precipitation mechanism is given in Fig. 7. It is expected that cold working introduces a high density of deformation-induced defects. These defects act as heterogeneous nucleation sites for the formation of $\mathrm{Cu}$-rich precipitates. The black precipitates are formed because of significant increase of $\mathrm{Ti}$ contents in the vicinities of white precipitates as indicated by the darker contrast around the white precipitates in the backscattered-SEM image shown in the inset of Fig. 4f; and this explains the reason for the formation of black precipitates in the adjacent areas of white TiPdCu-type precipitates as can be seen in Fig. 4e [34]. The XRD results reveal that the precipitation actually starts at temperatures between 573 

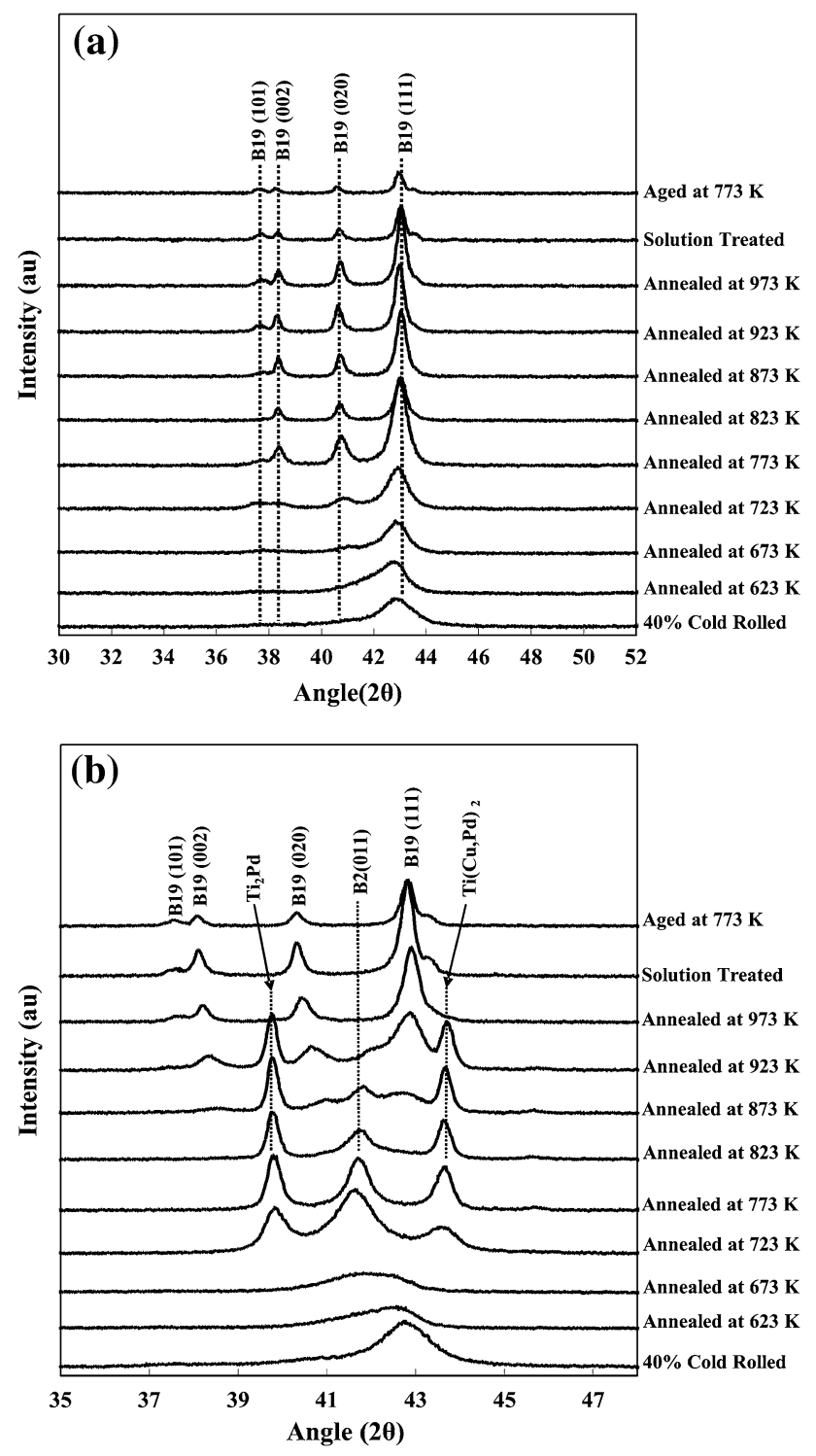

Fig. 3 Room temperature XRD profiles of a $0 \mathrm{Cu}$ alloy and $\mathbf{b} 10 \mathrm{Cu}$ alloy after $40 \%$ cold deformation, solution treatment, annealing at various temperatures, and aging at $773 \mathrm{~K}$ [34]

and $623 \mathrm{~K}$ and becomes significant at $673 \mathrm{~K}$. This observation is also favored by a noticeable increase in hardness values of $10 \mathrm{Cu}$ alloy annealed at 623 and $673 \mathrm{~K}$ as compared to that of the $0 \mathrm{Cu}$ alloy [34].

\section{Effects of Nanoscaled Precipitates on the Hardness and Shape Memory Properties of TiNiPdCu-Based Alloys}

Nanoscaled precipitate formation significantly increases the hardness of precipitates containing alloy [34]. The significant increase in the hardness of annealed 10Cu alloys as compared to that of $0 \mathrm{Cu}$ alloy shows the strong strengthening effect of the fine precipitates. The hardness of $773 \mathrm{~K}$ aged $10 \mathrm{Cu}$ sample (heat treated at $773 \mathrm{~K}$ after solution treatment without any prior cold deformation) confirms that the prior cold deformation plays a key role in the formation of fine precipitates [34].

Constant stress thermal cycling tests confirm the remarkable improvement in the high temperature cyclic stability of TiNiPdCu alloys mainly because of the formation of nanoscaled $\mathrm{Ti}_{2} \mathrm{Pd}$ - and $\mathrm{TiPdCu}$-type precipitates as shown in Fig. 8. Although the fine precipitates induce significant improvement in high temperature cyclic stability, two negative effects of these precipitates are also very prominent. First, the formation of these precipitates reduces the overall shape recovery strain and second, they severely depress the martensitic transformation temperatures. To overcome these negative effects the important controlling parameters need to be optimized. The important controlling parameters are the chemical composition, annealing temperature, and density of defects [34].

\section{Dependence of Precipitation Behavior on the $\mathrm{Cu}$ Content and Annealing Temperature}

$\mathrm{Cu}$ contents and annealing temperature can have profound effects on the nanoscale precipitation behavior in case of TiNiPdCu alloys [35]. Figure 9 shows the room temperature XRD profiles of various $\mathrm{Ti}_{50} \mathrm{Ni}_{25-x} \mathrm{Pd}_{25} \mathrm{Cu}_{x}$ alloys $(x=0,3,5,7.5,10)$ which were annealed at different temperatures between 673 and $973 \mathrm{~K}$ in Ar-filled quartz tubes for $3.6 \mathrm{ks}$. Hereafter, the alloys are referred according to their $\mathrm{Cu}$ contents (at.\%), i.e., $0 \mathrm{Cu}, 3 \mathrm{Cu}, 5 \mathrm{Cu}$, $7.5 \mathrm{Cu}$, and $10 \mathrm{Cu}$. The initial cold deformation ratio was $40 \%$ in all the samples. The $673 \mathrm{~K}$ annealing treatment of the $40 \%$ cold-deformed alloys confirms the presence of significant work hardening in all the samples. No evidence of precipitate formation is detected in the $673 \mathrm{~K}$ annealed $0 \mathrm{Cu}, 3 \mathrm{Cu}, 5 \mathrm{Cu}$, and $7.5 \mathrm{Cu}$ alloys. XRD profiles of the $673 \mathrm{~K}$ annealed $7.5 \mathrm{Cu}$ and $10 \mathrm{Cu}$ alloys indicate that a mixture of B2 parent and B19 martensite phases are present and the peaks are relatively broader than those of the other three alloys. The $773 \mathrm{~K}$ annealing treatment can produce well-defined sharp peaks of B19 martensite in the $0 \mathrm{Cu}$ and $3 \mathrm{Cu}$ alloys. This shows that most of the residual stresses are eliminated due to recovery and recrystallization [35]. It is reported in literature that the processes of recovery and recrystallization occur with the rearrangement and annihilation of less stable defects and the formation of new stress-free grains within the temperature range of 623-823 $\mathrm{K}$ in TiNiPd-based alloys [27]. In $773 \mathrm{~K}$ annealed $5 \mathrm{Cu}$ alloy, strong peaks of $\mathrm{Ti}_{2} \mathrm{Pd}-$ and $\mathrm{TiPdCu}-$ type precipitates can be observed along with B19 martensite peaks. The B19 martensite peaks remain broad 
Fig. 4 Backscattered-SEM images of $10 \mathrm{Cu}$ alloy annealed at a $673 \mathrm{~K}$, b $773 \mathrm{~K}$, c $823 \mathrm{~K}$, d $873 \mathrm{~K}$, e $923 \mathrm{~K}$, and f $973 \mathrm{~K}$ for $3.6 \mathrm{ks}$ after $40 \%$ cold deformation [34]
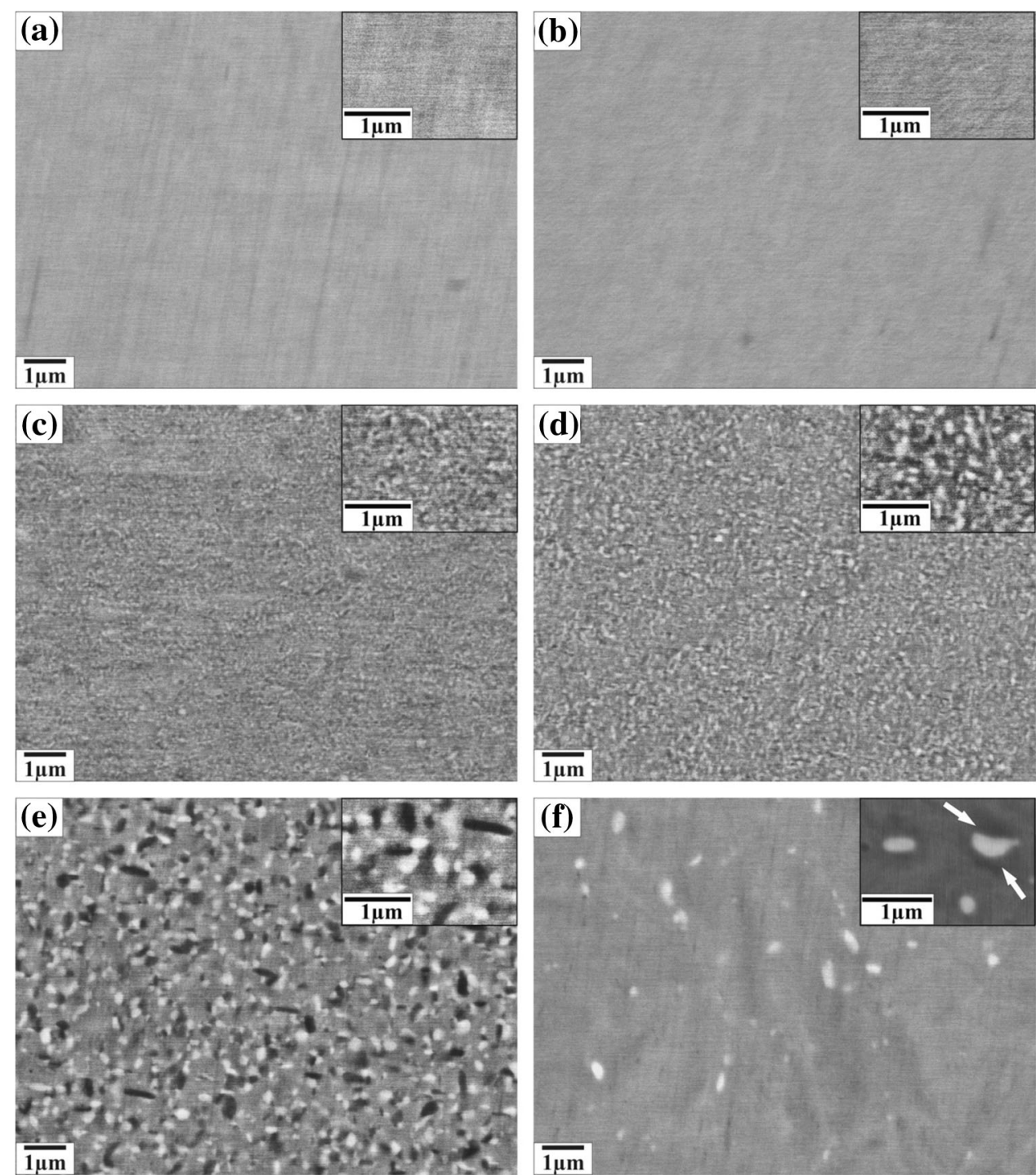

in this sample mainly because of significant amount of deformation-induced stress and the fragmentation of the grains into smaller diffracting units due to the significant prior cold deformation which could not be recovered upon annealing. The peak intensities of the precipitates and B2 phase increase while that of B19 martensite phase decrease with increasing $\mathrm{Cu}$ content. These results suggest that the formation of $\mathrm{Ti}_{2} \mathrm{Pd}$ - and $\mathrm{TiPdCu}$-type precipitates not only depressed the martensitic transformation temperatures but also retarded the recovery/recrystallization process. The XRD profiles of the alloys annealed at $873 \mathrm{~K}$ show no indications of precipitate formation in the $0 \mathrm{Cu}, 3 \mathrm{Cu}$, and $5 \mathrm{Cu}$ alloys. In the $7.5 \mathrm{Cu}$ and $10 \mathrm{Cu}$ alloys, the peaks of $\mathrm{Ti}_{2} \mathrm{Pd}$ - and TiPdCu-type precipitates can be observed along with B19 martensite and B2 peaks. After Annealing at $973 \mathrm{~K}$, all the alloys show only the B19 martensite phase [35]. Figure 10 shows the martensitic transformation start temperatures $\left(M_{\mathrm{s}}\right)$ (determined by the DSC) of the alloys in solution-treated and annealed conditions as a function of $\mathrm{Cu}$ content. The $0 \mathrm{Cu}, 3 \mathrm{Cu}$, and $5 \mathrm{Cu}$ alloys annealed at $673 \mathrm{~K}$ show relatively lower $M_{\mathrm{s}}$ temperatures as compared with that of the same alloys annealed at higher temperatures. The $M_{\mathrm{s}}$ temperatures of the $673 \mathrm{~K}$ annealed $7.5 \mathrm{Cu}$ and $10 \mathrm{Cu}$ alloys could not be determined by DSC. Annealing at $773 \mathrm{~K}$ causes an increase in the $M_{\mathrm{s}}$ temperatures of the $0 \mathrm{Cu}, 3 \mathrm{Cu}$, and $5 \mathrm{Cu}$ alloys. The $773 \mathrm{~K}$ annealed $7.5 \mathrm{Cu}$ and $10 \mathrm{Cu}$ alloys show significantly lower $\mathrm{M}_{\mathrm{s}}$ temperatures as compared with those of the other three alloys with lower $\mathrm{Cu}$ contents. Annealing at $873 \mathrm{~K}$ results in a significant increase in the $M_{\mathrm{s}}$ temperature of the $0 \mathrm{Cu}$, $3 \mathrm{Cu}$, and $5 \mathrm{Cu}$ alloys. A significant increase in the transformation temperatures of the $873 \mathrm{~K}$ annealed $7.5 \mathrm{Cu}$ and $10 \mathrm{Cu}$ alloys can also be observed. $\mathrm{Cu}$ content is a strong factor in the precipitation behavior of annealed TiNiPdCubased alloys. An increase in $\mathrm{Cu}$ content can cause a significant increase in the tendency of precipitation in these 
Fig. 5 TEM images of $10 \mathrm{Cu}$ alloy a solution-treated, b $40 \%$ cold deformed, and (c, d) annealed at $773 \mathrm{~K} \mathrm{[34]}$
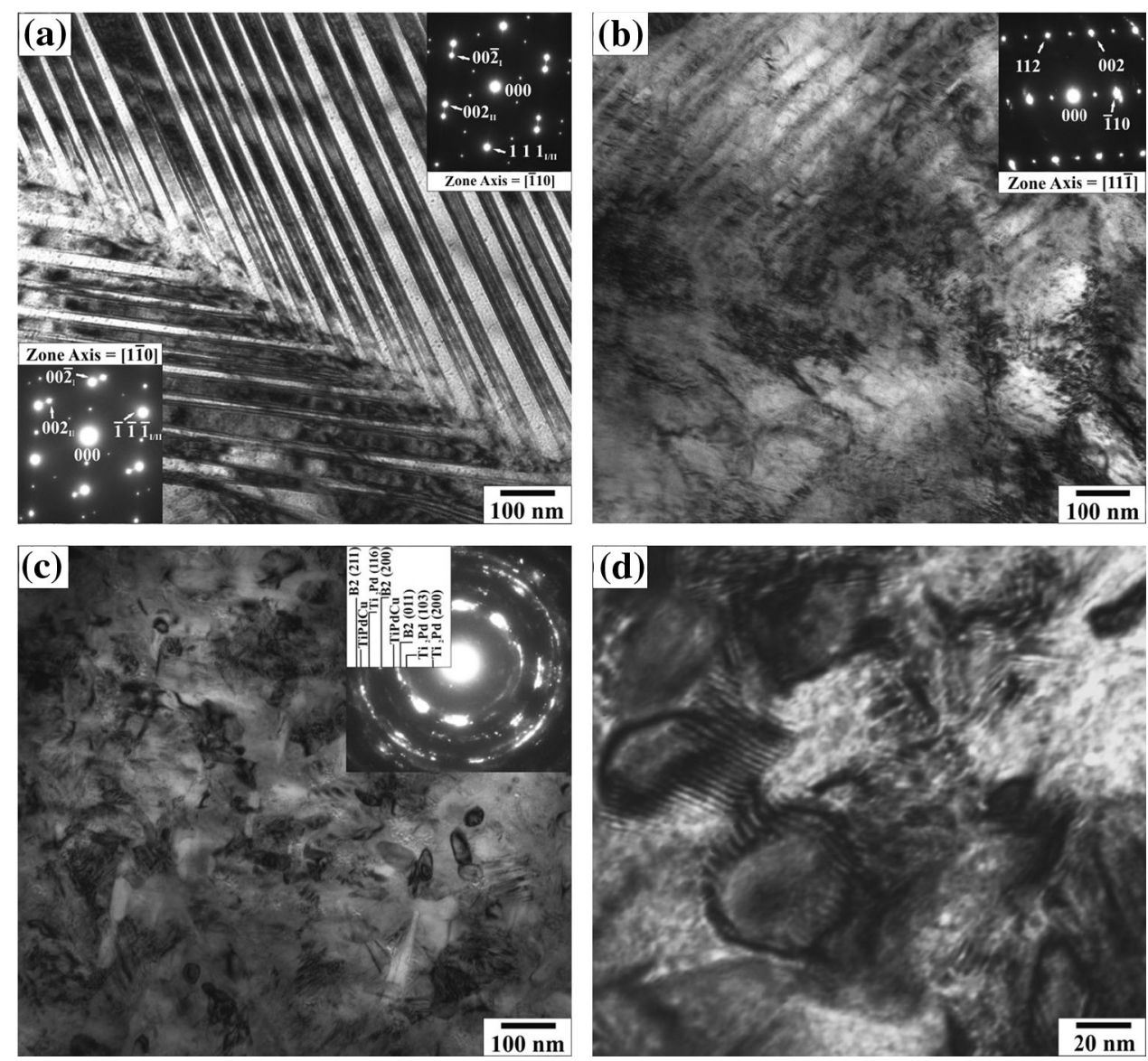

alloys. In TiNiPdCu-based alloys, higher densities of the $\mathrm{TiPdCu}$ - and $\mathrm{Ti}_{2} \mathrm{Pd}$-type precipitates severely depress the martensitic transformation temperatures, especially in alloys with $\mathrm{Cu}$ contents greater than 5 at.\%, when annealed within the temperature range of $673-873 \mathrm{~K}$. The reason is that as the $\mathrm{Cu}$ content of the alloy increases, it also increases the tendency for preferential nucleation of $\mathrm{Cu}$ rich TiPdCu-type precipitates at heterogeneous nucleation sites created by the deformation-induced defects during cold deformation. As a result the density of TiPdCu-type precipitates increases with increasing $\mathrm{Cu}$ content [35]. The formation of $\mathrm{TiPdCu}$ precipitates causes a significant increase in the $\mathrm{Ti}$ content of the matrix within their vicinities and promotes the formation of $\mathrm{Ti}_{2} \mathrm{Pd}$-type precipitates [34]. Along with the $\mathrm{Cu}$ content, the annealing temperature is another factor affecting the tendency of precipitation in the TiNiPd-based alloys. For example, at the annealing temperature of $873 \mathrm{~K}$ the $5 \mathrm{Cu}$ alloy did not show the formation of precipitates, while the same alloy showed a significant presence of both types of precipitates when annealed at $773 \mathrm{~K}$. In fact, increasing the annealing temperature eliminates the relatively less stable heterogeneous nucleation sites before the formation of stable nuclei of $\mathrm{Cu}$-rich $\mathrm{TiPdCu}$ precipitates. The precipitation behavior in TiNiPdCu-based alloys strongly depends upon a competition between the nucleation rate of TiPdCu-type precipitates and the rate of removal of the heterogeneous nucleation sites provided by the deformation-induced defects, especially at relatively higher annealing temperatures. The formation of the above-mentioned nanoscaled precipitates also cause an increase in the transformation temperature intervals $[34,35]$. It is well known that the transformation temperature intervals $\left(M_{\mathrm{s}}-M_{\mathrm{f}}\right.$ and $\left.A_{\mathrm{f}}-A_{\mathrm{s}}\right)$ are strongly related to the frictional energy that prevents the habit plane migration and to the elastic energy stored during the growth of the martensite phase [44, 45]. It is expected that the formation of higher densities of $\mathrm{TiPdCu}-$ and $\mathrm{Ti}_{2} \mathrm{Pd}$-type nanoscaled precipitates offers a higher resistance to habit plane migration and increases the stored elastic energy in annealed TiNiPdCu-based alloys. Based on the XRD and DSC results it can be said that the $5 \mathrm{Cu}$ alloy can be a potential candidate for high temperature shape memory applications because of its relatively higher transformation temperatures along with a significant volume fraction of precipitates when annealed at, for example, $773 \mathrm{~K}$ [35]. 

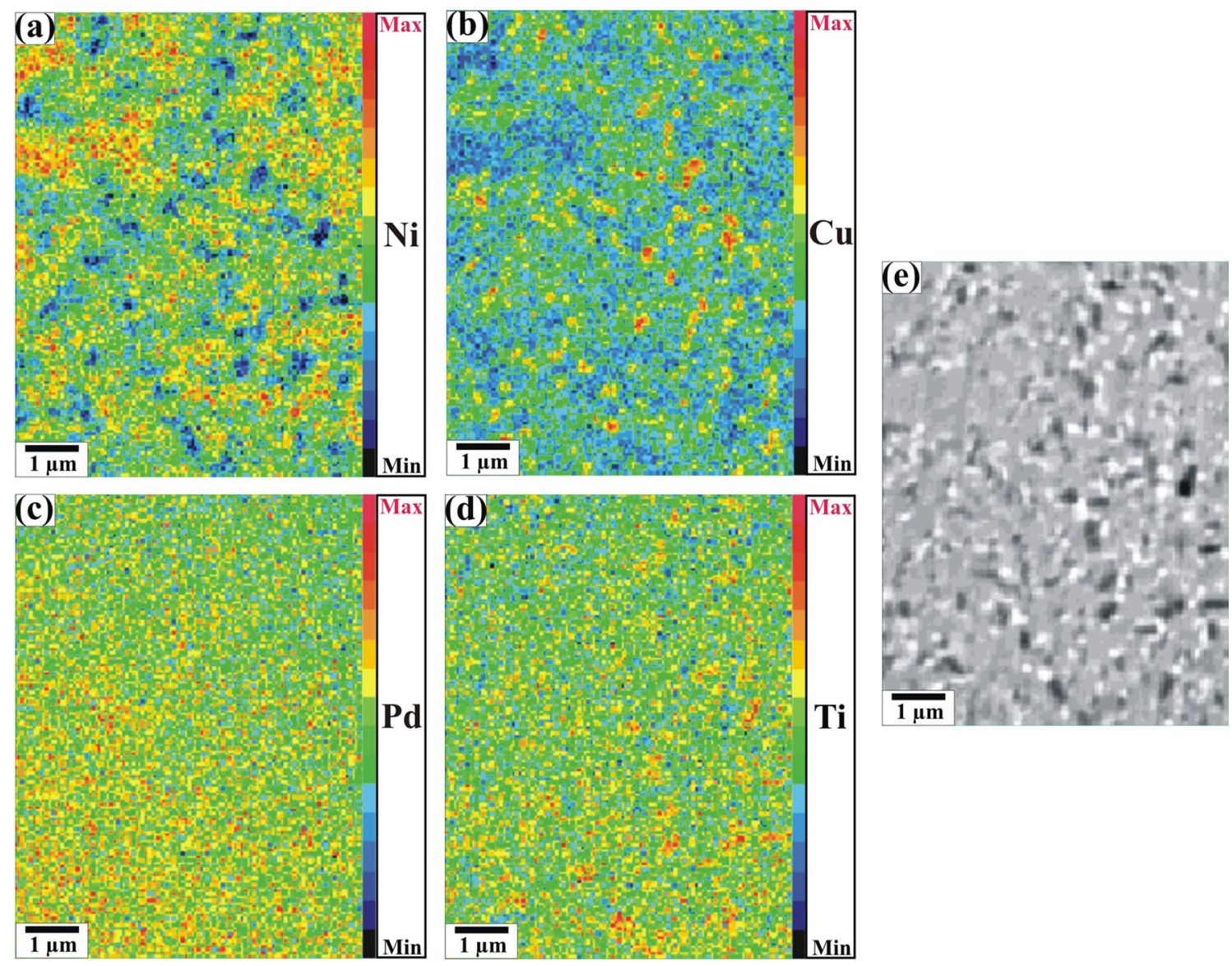

Fig. 6 X-ray mapping images of 10Cu alloy annealed at $923 \mathrm{~K}$ showing the elemental distribution of alloying elements [34]

Table 2 EPMA spot chemical composition analysis of black and white precipitates formed in 10Cu alloys when annealed after $40 \%$ cold deformation [34]

\begin{tabular}{lllllll}
\hline S. No & Analysis region & Ti (at.\%) & Ni (at.\%) & Pd (at.\%) & Cu (at.\%) & Precipitate \\
\hline 1 & White precipitates & 37.3 & 8.9 & 26.4 & 27.3 & $\mathrm{TiPdCu}_{2}$ \\
2 & Black precipitates & 56.8 & 12.1 & 22.9 & 8.2 & $\mathrm{Ti}_{2} \mathrm{Pd}$ \\
\hline
\end{tabular}

\section{Effect of Nanoscaled Precipitates on the Resistance to Recovery and Recrystallization Processes}

The formation of nanoscaled precipitates significantly retards the recovery and recrystallization processes in the TiNiPdCubased alloys. The precipitates are formed at the heterogeneous nucleation sites provided by the cold-working induced defects and these precipitates, in turn, stabilize the remaining defect sites due to a pinning effect and retarded the recovery and recrystallization type processes as can be seen in the TEM results shown in Figs. 11 and 12. The microstructure of $673 \mathrm{~K}$ annealed $0 \mathrm{Cu}$ alloy shows a heavily deformed microstructure which confirms that the annealing temperature is not high enough to recover the deformed microstructure. The $773 \mathrm{~K}$ annealed 0Cu alloy microstructure shows the occurrence of partial recrystallization of the deformed microstructure as indicated by the black arrows in Fig. 11c. Figure 12 shows the microstructures of the 673 and $773 \mathrm{~K}$ annealed 5Cu alloy. The TEM results confirm that neither 673 nor $773 \mathrm{~K}$ annealing temperatures is able to recover the deformed microstructure. This is because of the presence of nanoscaled precipitates in the case of $773 \mathrm{~K}$ annealed $5 \mathrm{Cu}$ alloy as can be seen in the TEM results [35].

\section{Creep Behavior and Precipitation-Assisted Improved Cyclic Training Response at High Temperatures}

Precipitation-strengthened TiNiPdCu-based alloys exhibit significantly improved high temperature cyclic response, as shown in Fig. 13. Precipitation-strengthened $5 \mathrm{Cu}$ alloy 


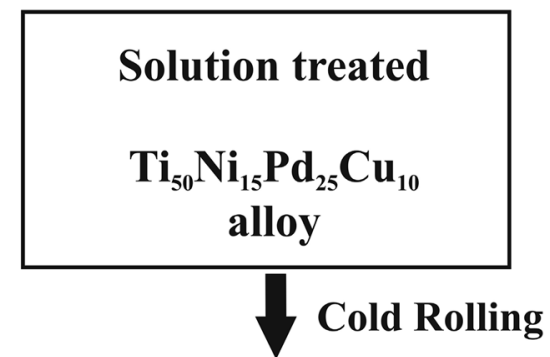

(a) Cold deformation induced high density of defects.

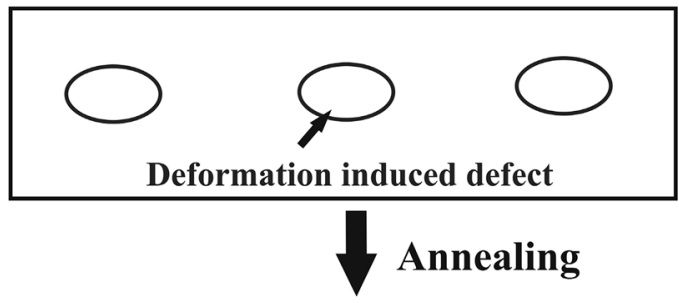

(b) Preferential diffusion of $\mathrm{Cu}$ towards the induced defects promotes the precipitation of $\mathrm{Cu}$ rich TiPdCu type precipitates.

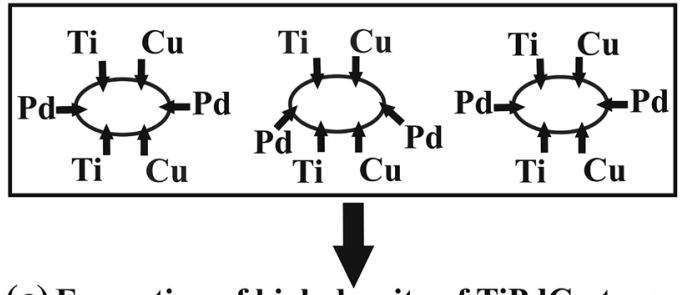

(c) Formation of high density of TiPdCu type precipitates resulted in the Ti rich regions surrounding them.

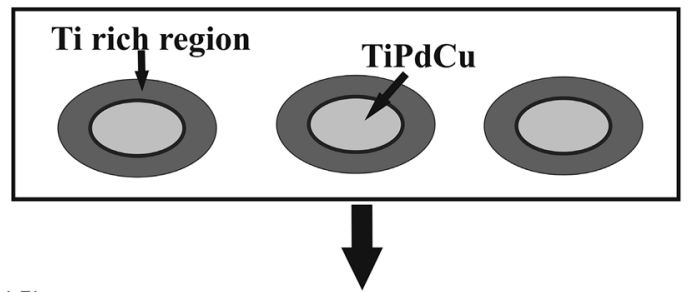

(d) Formation of $\mathrm{Ti}$ rich $\mathrm{Ti}_{2} \mathrm{Pd}$ type precipitates in the vicinity of $\mathrm{TiPdCu}$ type precipitates

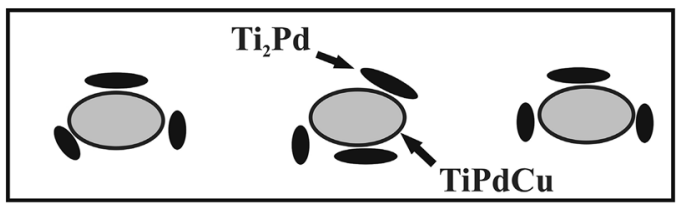

Fig. 7 A proposed precipitation mechanism of $\mathrm{TiPdCu}-$ and $\mathrm{Ti}_{2} \mathrm{Pd}-$ type precipitates in a cold-deformed $10 \mathrm{Cu}$ alloy after annealing as a result of a spinodal type of decomposition [34]

shows very stable cyclic and training responses within a temperature range of $300-673 \mathrm{~K}$ at an applied stress of $500 \mathrm{MPa}$. This temperature range certainly exceeds the creep temperature range of TiNiPd-based alloys. This alloy maintains the recovery strain and transformation temperatures at reasonably high levels along with the significant volume fraction of nanoscaled $\mathrm{Ti}_{2} \mathrm{Pd}$ - and $\mathrm{TiPdCu}$-type precipitates [35].

The above-mentioned nanoscaled precipitates also help to retain the induced strain hardening effects and stabilize the cyclic training response even in severe working conditions. The $5 \mathrm{Cu}$ alloy shows a significantly stable cyclic response and the recovery and plastic strains remain stable as compared to that of $0 \mathrm{Cu}$ alloy. The main reason for this stability can be linked to the improvement in resistance against creep deformation, especially at higher cyclic temperatures. The precipitation strengthening effect, in case of annealed $5 \mathrm{Cu}$ alloy, also stabilizes the hysterisis $\left(A_{\mathrm{f}}-M_{\mathrm{s}}\right)$ values (determined from the constant stress thermal cycling curves shown in Fig. 13) with respect to the increasing number of training cycles within the temperature range of $300-673 \mathrm{~K}$ and at an applied stress of $500 \mathrm{MPa}$ as shown in Fig. 14 [35].

Creep tests of the $773 \mathrm{~K}$ annealed $0 \mathrm{Cu}$ and $5 \mathrm{Cu}$ alloys confirm the improved creep resistance of the precipitate containing $5 \mathrm{Cu}$ alloy. Creep tests of both the alloys were carried out at a stress level of $500 \mathrm{MPa}$ and at a temperature of $673 \mathrm{~K}$ for $50 \mathrm{ks}$ or until fracture. Figure 15 shows the creep curves of both the annealed alloys. The $5 \mathrm{Cu}$ alloy exhibits significantly improved creep resistance that is evident from a much slower steady-state creep rate of $2.1 \times 10^{-6} \mathrm{~s}^{-1}$ and much longer steady-state creep region as compared to that of $0 \mathrm{Cu}$ alloy, which showed a steadystate creep rate of $6.5 \times 10^{-6} \mathrm{~s}^{-1}$ and a very small steadystate creep region. Nanoscale precipitation of TiPdCu- and $\mathrm{Ti}_{2} \mathrm{Pd}$-type precipitates significantly increases the resistance against the high temperature transformation-induced plasticity and creep deformation mainly because of the high temperature stability of the fine precipitates [35].

\section{Effect of Cold Rolling Ratio on the Nanoscale Precipitation Behavior of TiNiPdCu-Based Alloys}

The density of defects plays an important role in the nanoscale precipitation behavior of TiNiPdCu-based alloys [34]. Our research group has recently reported a systematic study on the effect of the density of deformation-induced defects on the nanoscale precipitation behavior in TiNiPdCu-based alloys [46]. It is well known that the percentage of cold deformation is directly related to the density of defects. In the above-mentioned study the density of deformation-induced defects was changed by changing the cold rolling ratio and the nanoscale precipitation behavior was studied in $10 \mathrm{Cu}$ alloy using various characterization techniques [46].

After melting in an Ar-arc melting furnace and homogenizing at $1223 \mathrm{~K}$ for $7.2 \mathrm{ks}$, the $10 \mathrm{Cu}$ alloy was solution treated at $1173 \mathrm{~K}$ for $3.6 \mathrm{ks}$. Hereafter, these 
Fig. 8 Strain-temperature curves of a solution-treated $0 \mathrm{Cu}$ alloy, b solution-treated $10 \mathrm{Cu}$ alloy, $\mathbf{c} 0 \mathrm{Cu}$ alloy annealed at $873 \mathrm{~K}$ and $\mathbf{d} 10 \mathrm{Cu}$ alloy annealed at $873 \mathrm{~K}$ [34]
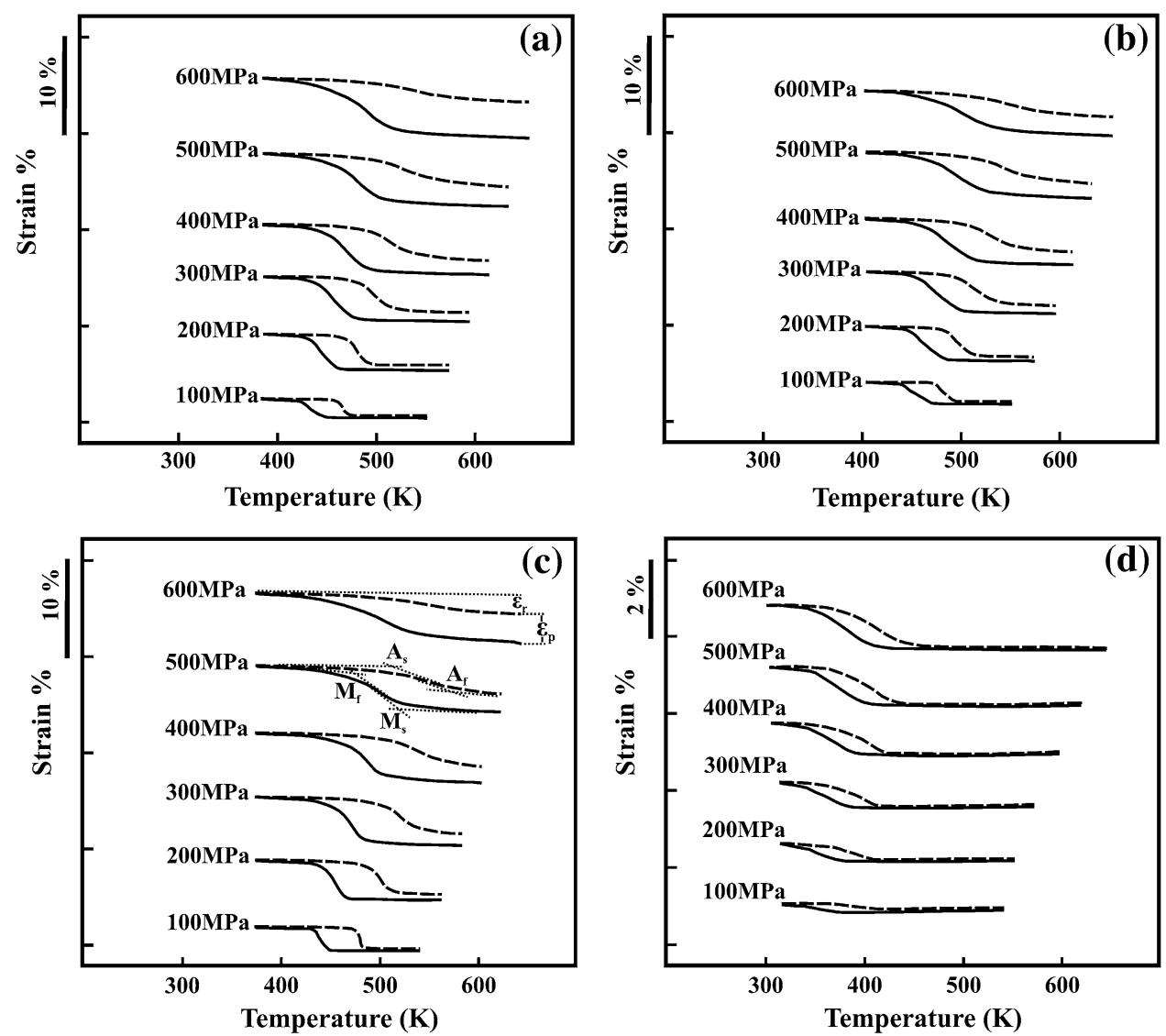

samples are referred as ST samples. The final cold rolling ratios were set as 0,10 , and $40 \%$. All the samples were cold rolled at room temperature and the samples were in a fully martensitic state. The sample with $0 \%$ cold rolling ratio is actually the ST sample without any cold rolling. Hereafter, these samples are referred according to their given cold rolling ratios i.e., $0 \mathrm{CR}, 10 \mathrm{CR}$, and $40 \mathrm{CR}$. These samples were subsequently annealed at $923 \mathrm{~K}$ for $3.6 \mathrm{ks}$. Hereafter, the annealed samples are referred to as STA, 10CRA, and 40CRA, respectively [46]. Figure 16 shows the XRD profiles of ST, STA, 10CRA, and 40CRA samples. The XRD profiles show a strong dependence of density of precipitates i.e., $\mathrm{TiPdCu}$ - and $\mathrm{Ti}_{2} \mathrm{Pd}$-type precipitates, on the amount of prior cold deformation. Figure 17 shows the backscattered-SEM images of ST samples. A well-defined B19 martensite structure can be seen. The SEM images show no indication of $\mathrm{Ti}_{2} \mathrm{Pd}-$ or TiPdCu-type precipitates. A low volume fraction of coarse $\mathrm{Ti}_{2} \mathrm{Ni}$-type precipitates can be seen in the sample which was formed during solidification just after the arc melting process which could not be dissolved even at the solution treatment temperature. Figure 18 shows the backscatteredSEM images of STA sample which clearly show the formation of TiPdCu-type precipitates. They are formed only along the grain boundaries because the grain boundaries are the high energy sites containing a relatively higher number of defects [46]. This observation agrees with our proposed precipitation mechanism which shows a strong relationship between the presence of defects and nucleation of TiPdCu-type precipitates [34]. This also confirms that the TiPdCu-type precipitates are formed prior to the formation of $\mathrm{Ti}_{2} \mathrm{Pd}$-type precipitates. Twin boundaries are also regarded as planer defects in materials but the TiPdCutype precipitates are not formed along the twin boundaries in STA samples as can be seen in Fig. 18. The reason is that the STA samples were annealed at $923 \mathrm{~K}$ temperature which is much higher than the $A_{\mathrm{f}}$ temperature of the alloy and the sample remains in $\mathrm{B} 2$ phase during the whole annealing treatment. The B2 phase is characterized with a twin-less microstructure with a cubic crystal structure. Although the twin boundaries are absent due to the twinless nature of the B2 phase, the grain boundaries were present as the sample was polycrystalline. That is why the precipitates are formed along the grain boundaries but not along the twin boundaries [46].

The 2nd phase particles and inclusions, i.e., coarse $\mathrm{Ti}_{2} \mathrm{Ni}$-type precipitates, can also act as the heterogeneous nucleation sites for the formation of TiPdCu-type precipitates as can be seen in Fig. 18d. Increasing the cold deformation ratio increases the number of defects in the 
Fig. 9 Room temperature XRD profiles of a $673 \mathrm{~K}$ annealed, b $773 \mathrm{~K}$ annealed, c $873 \mathrm{~K}$ annealed, and $\mathbf{d} 973 \mathrm{~K}$ annealed $\mathrm{Ti}_{50} \mathrm{Ni}_{25-x} \mathrm{Pd}_{25} \mathrm{Cu}_{x}$ alloys [35]
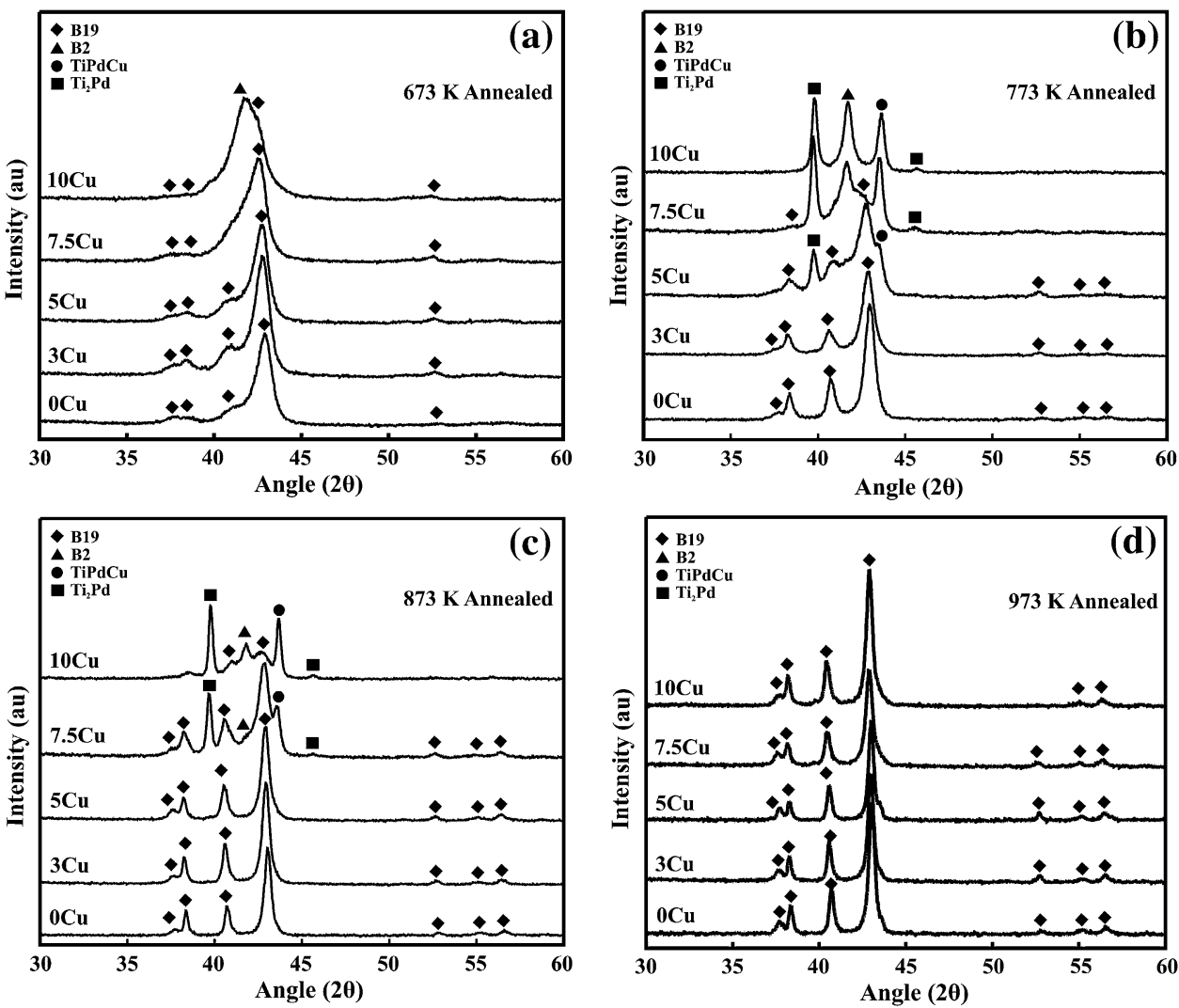

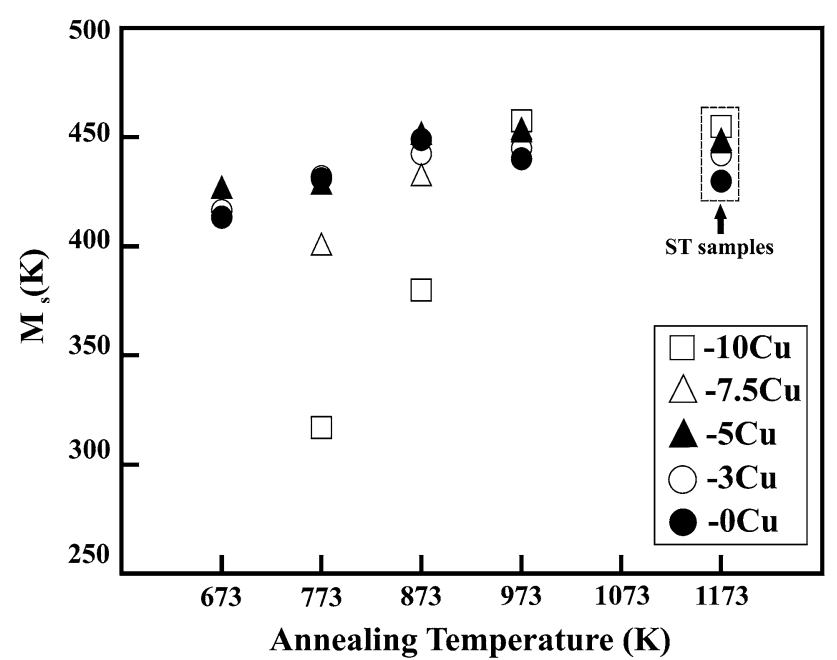

Fig. $10 M_{\mathrm{s}}$ temperatures of all the alloys as a function of annealing temperature [35]

microstructure and de-twins the B19 martensite structure. The $10 \%$ cold rolling ratio cannot completely destroy the self-accommodated twinned B19 martensite structure and a significant degree of self-accommodated twinned martensitic structure is still present in 10CR samples. The $10 \%$ cold rolling ratio introduces a significant amount of defects and causes a partial detwinning of the twinned B19 martensite structure. The $40 \%$ cold rolling ratio completely destroys the self-accommodated twinned structure of B19 martensite because of excessive cold deformation. The $40 \%$ cold rolling ratio introduces a significant amount of defects and causes an almost complete detwinning of the twinned B19 martensite structure [46].

Figures 19a-d show the backscattered-SEM images of 10CRA sample. The TiPdCu- and $\mathrm{Ti}_{2} \mathrm{Pd}$-type precipitates (white and black contrast, respectively) are preferentially formed along the grain boundaries (indicated by the arrows in Fig. 19a) as well as along the twin boundaries (indicated by the arrows in Figs. 19b-d). The formation of precipitates actually traces the shapes of different self-accommodated morphologies of B19 martensite as indicated by black arrows in Fig. 19c. The precipitates are formed not only along the twin boundaries of long twin plates but also along the internal twin boundaries as indicated by the black arrows in Fig. 19d. Actually the initial microstructure of the 10CR sample, prior to the annealing treatment, is cold deformed up to $10 \%$ that contains significant density of defects. Relatively more and stable defects are generated both at the grain boundaries and twin boundaries as compared to that of grain interiors during the cold deformation process. The defects, generated during the deformation process both at the grain boundaries and twin boundaries, are actually retained during the annealing process and serve as heterogeneous nucleation sites for the 
Fig. 11 TEM images of $0 \mathrm{Cu}$ alloy (a, b) annealed at $673 \mathrm{~K}$ and (c, d) annealed at $773 \mathrm{~K}$ [35]
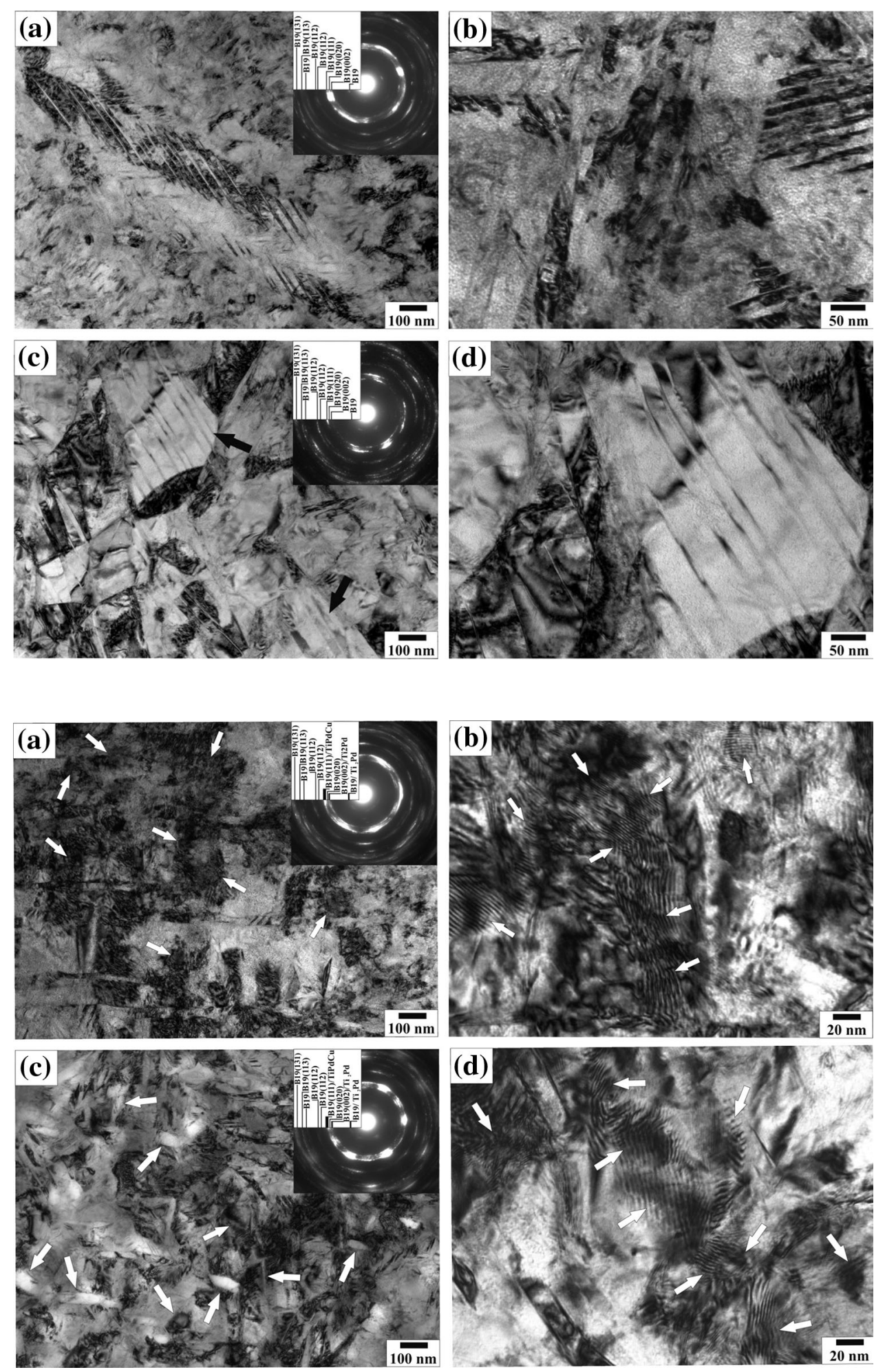

Fig. 12 TEM images of $5 \mathrm{Cu}$ alloy (a, b) annealed at $673 \mathrm{~K}$ and $(\mathbf{c}, \mathbf{d})$ annealed at $773 \mathrm{~K}$ [35] nucleation of TiPdCu-type precipitates which in turn promotes the formation of $\mathrm{Ti}_{2} \mathrm{Pd}$-type precipitates [46]. Figure 20a, $\mathrm{b}$ show the backscattered SEM images of 40CRA samples that fully support the respective XRD results given in Fig. 16. The microstructures clearly show significantly higher densities of $\mathrm{TiPdCu}$ - and $\mathrm{Ti}_{2} \mathrm{Pd}$-type precipitates as compared to that of STA and 10CRA samples. The precipitate formation does not follow any preferred location and are formed evenly in all the areas. Actually, in case of 40CRA sample the initial microstructure contains a very high density 
Fig. 13 Constant stress thermal cycling at $500 \mathrm{MPa}$ within the temperature range $300-673 \mathrm{~K}$ of a solution-treated $0 \mathrm{Cu}$ alloy, b solution-treated $5 \mathrm{Cu}$ alloy, c $673 \mathrm{~K}$ annealed $0 \mathrm{Cu}$ alloy, d $673 \mathrm{~K}$ annealed $5 \mathrm{Cu}$ alloy, e $773 \mathrm{~K}$ annealed $0 \mathrm{Cu}$ alloy, and $\mathbf{f} 773 \mathrm{~K}$ annealed $5 \mathrm{Cu}$ alloy [35]
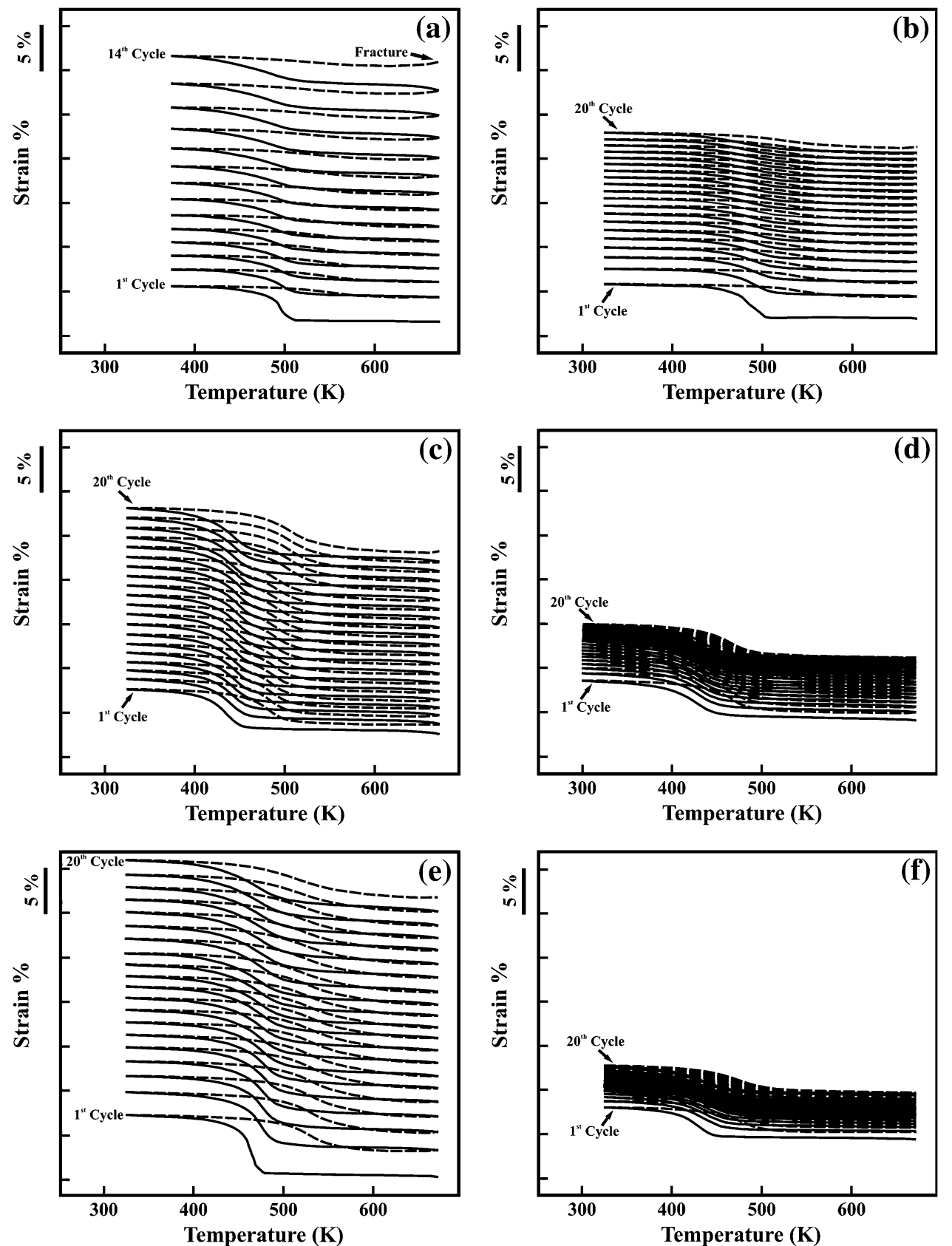

of defects in all the areas, i.e., grain boundaries, twin boundaries, grain interiors etc., and as a result the precipitates are formed at the evenly distributed heterogeneous nucleation sites of deformation-induced defects [46].

The DSC results of the above-mentioned samples also confirm a noticeable effect of cold rolling ratio on the density of precipitates. The STA sample exhibits almost the similar transformation temperatures as compared to that of ST samples. This is due to a low density of TiPdCu-type precipitates which do not significantly affect the transformation temperatures. The 10CRA and 40CRA samples show a significant depression in martensitic transformation temperatures. The 10CRA samples exhibit much lower transformation temperatures as compared to that of ST and STA samples. The main reason for this is the formation of higher densities of precipitates as a result of higher prior cold deformation ratio as shown in the respective XRD and SEM results above. The 40CRA samples exhibit a further depression in martensitic transformation temperatures as compared to that of 10CRA samples mainly because of the increase in the density of precipitates due to a higher prior cold deformation ratio [46].

Constant stress thermal cycling test results also exhibit the effect of cold rolling ratio on the precipitation behavior 

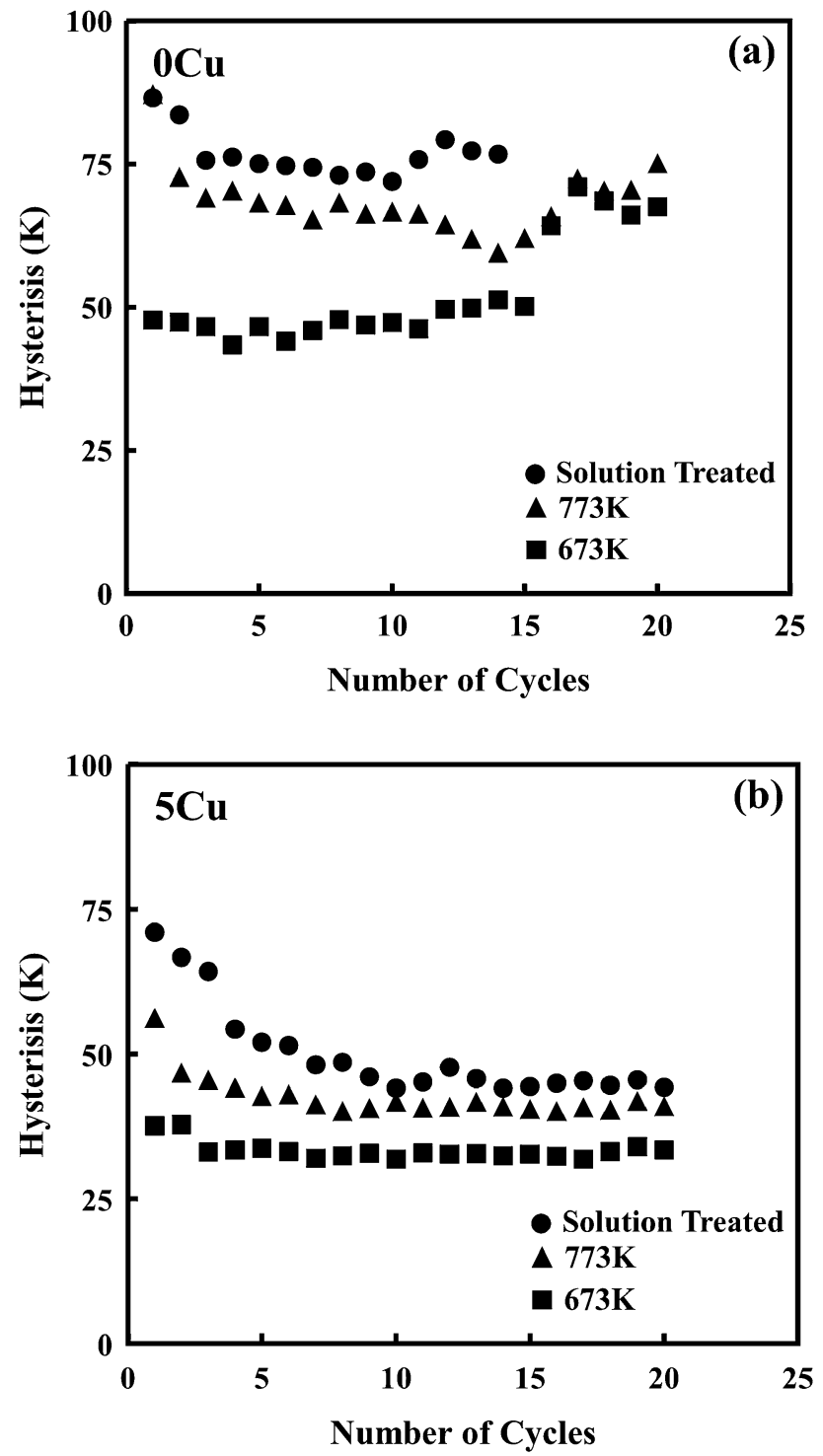

Fig. 14 Evolution of hysteresis of the $\mathbf{a} 0 \mathrm{Cu}$ and $\mathbf{b} 5 \mathrm{Cu}$ alloys in the solution-treated condition and after annealing at 673 and $773 \mathrm{~K}$ with respect to the number of cycles at an applied stress of $500 \mathrm{MPa}$ within the temperature range 300-673 K [35]

and shape memory characteristics of TiNiPdCu-based alloys [46]. The ST and STA samples show almost the similar levels of recovery and plastic strains due to the formation of very low density of TiPdCu-type precipitates in the STA sample. The 10CRA and 40CRA samples exhibit a significantly different shape memory behavior. Both the samples show a noticeably improved dimensional stability, relatively lower recovery strain, and lower transformation temperatures as compared to that of ST and STA samples mainly because of the formation of higher densities of precipitates. The 10CRA sample shows slightly higher levels of recovery strain and transformation temperatures as compared to that of 40CRA samples due to the

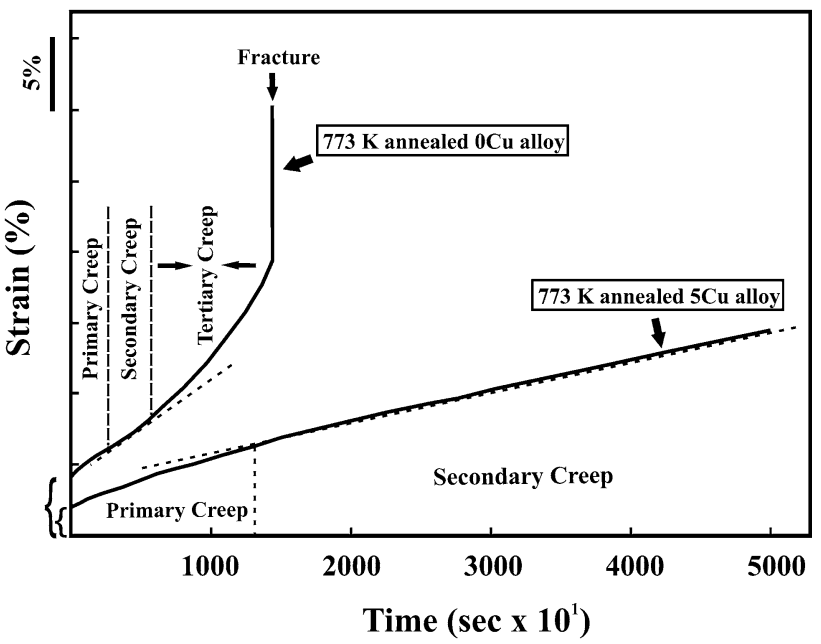

Fig. 15 Creep tests for $50 \mathrm{ks}$ or till fracture at an applied stress of $500 \mathrm{MPa}$ and a temperature of $673 \mathrm{~K}$ for the $773 \mathrm{~K}$ annealed $0 \mathrm{Cu}$ and $5 \mathrm{Cu}$ alloys [35]

intermediate increase in the density of precipitates as a result of a relatively increased prior cold rolling ratio. The experimental results and discussion, given above, clearly show that the cold rolling ratio can be effectively used to control the precipitation behavior in TiNiPdCu-based shape memory alloys [46].

\section{Effect of Pd Contents on the Precipitation Behavior of TiNiPdCu-Based Alloys}

Another research study of our group revealed the effects of $\mathrm{Pd}$ content on the precipitation behavior of TiNiPdCubased alloys. $\mathrm{Ti}_{50} \mathrm{Ni}_{45-x} \mathrm{Pd}_{x} \mathrm{Cu}_{5}(x=25,30,35)$ alloys were fabricated by the Ar-arc melting method. Hereafter, the alloys are referred according to their Pd content such as $25 \mathrm{Pd}, 30 \mathrm{Pd}$, or $35 \mathrm{Pd}$. After the homogenizing treatment at $1223 \mathrm{~K}$ for $7.2 \mathrm{ks}$, all the alloy samples were cold rolled up to $40 \%$ and subsequently heat treated at various temperatures between 673 and $1173 \mathrm{~K}$ for $3.6 \mathrm{ks}$. The detailed experimental procedure followed can be found in the relevant literature [47]. Martensitic transformation temperatures were determined by DSC. The DSC results clearly show that the martensitic transformation temperatures increase with the annealing temperature and the alloys with higher Pd contents show relatively higher transformation temperatures. The results also show that the value of $M_{\mathrm{s}}$ temperature saturates at about $873 \mathrm{~K}$ for the $25 \mathrm{Pd}$ and $30 \mathrm{Pd}$ alloys while it saturates at $973 \mathrm{~K}$ for the $35 \mathrm{Pd}$ alloy [47].

Figure 21 shows the XRD profiles of all three alloys annealed at various temperatures. The results show that the annealing treatment at $673 \mathrm{~K}$ is unable to remove the 
Fig. 16 XRD profiles of a ST, b STA, c 10CRA, and d 40CRA samples [46]
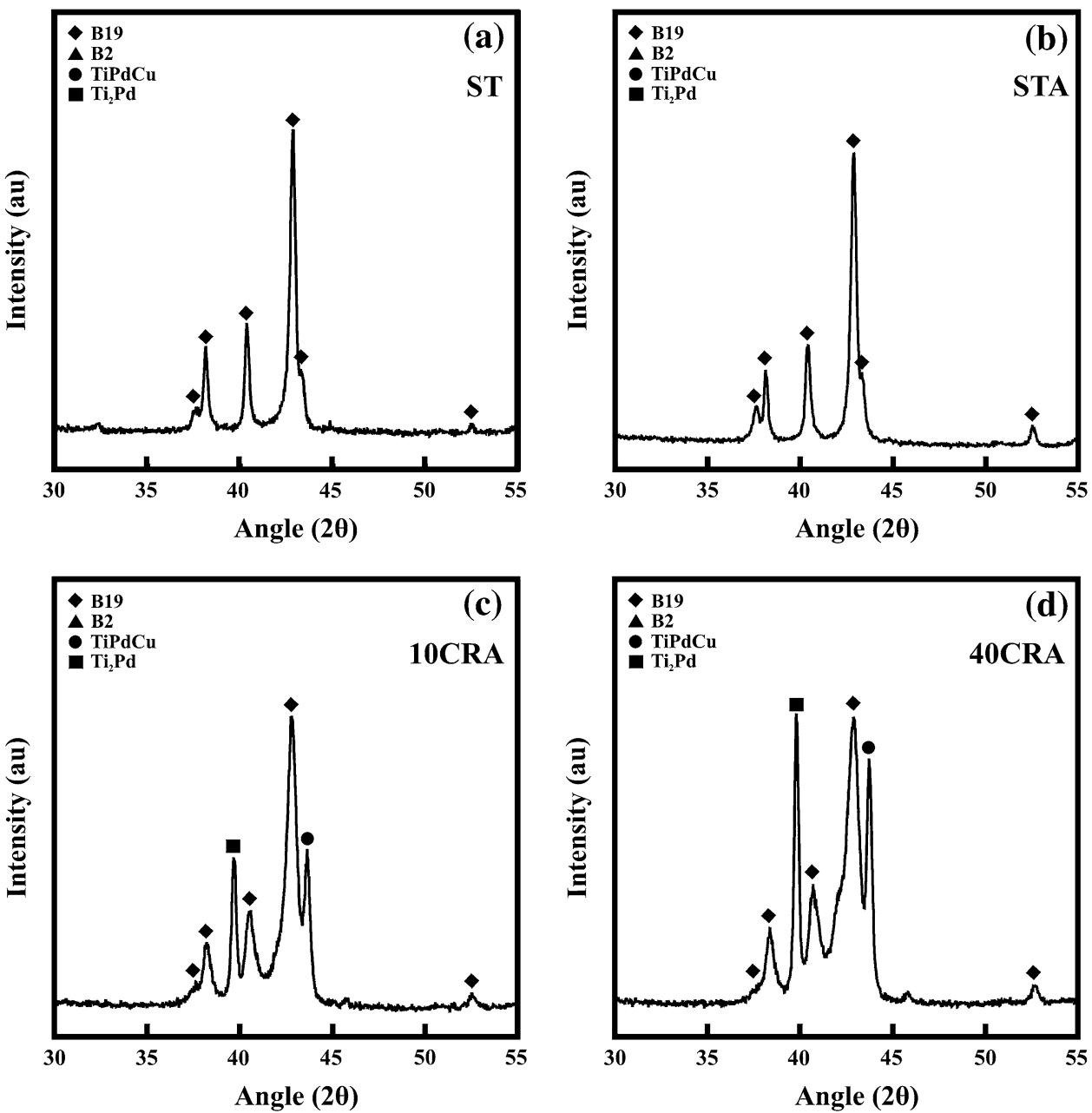

deformation-induced defects in all the three alloys as indicated by the broad peaks of the B19 martensite phase. Heat treatment at $773 \mathrm{~K}$ produces the clear peaks of $\mathrm{Ti}_{2} \mathrm{Pd}$ and $\mathrm{TiPdCu}$-type precipitates along with the peaks of the B19 phase in all the three alloys. The relative peak intensity of the precipitates as compared to that of B19 phase increases with increasing $\mathrm{Pd}$ content. In case of $25 \mathrm{Pd}$ and 30Pd alloys, $873 \mathrm{~K}$ annealing treatment results in relatively sharper peaks in B19 as compared to that of $673 \mathrm{~K}$ annealed samples. XRD profile of the $873 \mathrm{~K}$ annealed $35 \mathrm{Pd}$ alloy shows relatively weaker peaks of $\mathrm{Ti}_{2} \mathrm{Pd}$ - and TiPdCu-type precipitates as compared to that of $773 \mathrm{~K}$ annealed 35Pd alloy. Annealing at $973 \mathrm{~K}$ produces only the B19 martensite phase in all the alloys [47].

Figure 22a-c show the backscattered-SEM images of the $773 \mathrm{~K}$ annealed 25Pd, 30Pd, and 35Pd alloys. The SEM results confirm the XRD results and a strong presence of two types of precipitates can be seen in all the alloys when annealed at $773 \mathrm{~K}$. The SEM microstructure shows that the average size of both types of precipitates is about $100 \mathrm{~nm}$ [47].
The XRD results do not indicate the presence of precipitates in the $873 \mathrm{~K}$ annealed 25Pd and 30Pd alloys but the SEM images, given in Fig. 22d-f, reveal that a low volume fraction of TiPdCu-type precipitates is formed in these alloys. It can also be seen that the volume fraction of TiPdCu-type precipitates increases with increasing $\mathrm{Pd}$ content. The SEM image of 30Pd alloy also reveals the formation of $\mathrm{Ti}_{2} \mathrm{Pd}$-type precipitates along with the formation of TiPdCu-type precipitates. The SEM images also show that the sizes of both types of precipitates increase and their densities decrease with increasing heat treatment temperature. From XRD and SEM results, it can be concluded that the increase in Pd content promotes the formation of both types of precipitates and expands the annealing temperature range within which the precipitates are formed [47]. Another effect of the increase in $\mathrm{Pd}$ content in annealed TiNiPdCu-based alloys is the decrease in recovery strain as shown in Fig. 23. The recovery strain values were determined by the constant stress thermal cycling tests at various constant stress levels. It can also be seen that all the alloys show almost similar levels of 
Fig. 17 Backscattered SEM images of ST sample with different magnifications [46]
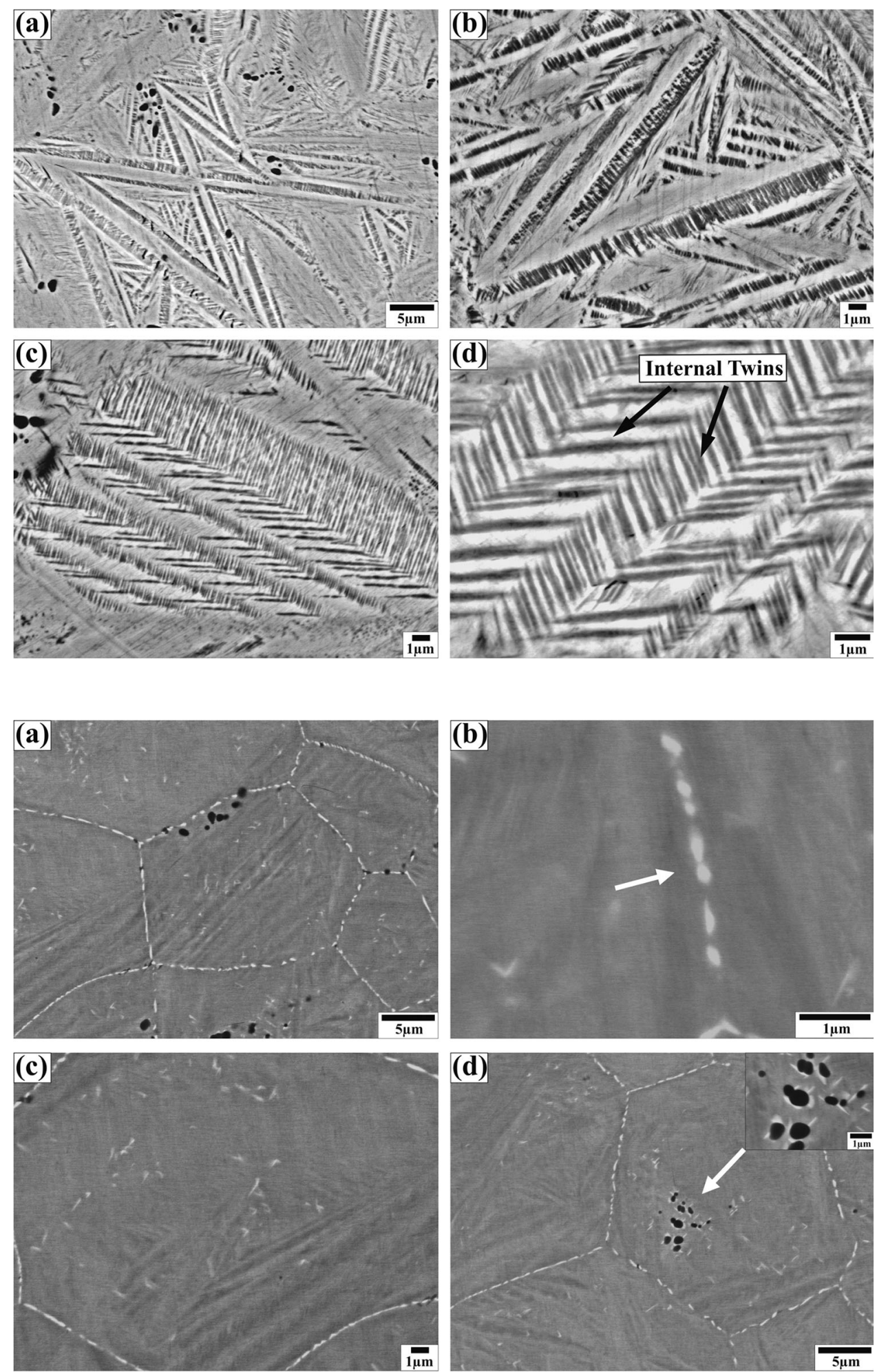

resistance against the plastic deformation under each stress levels despite the fact that the 30Pd and 35Pd alloys face more severe transformation conditions than that of the 25Pd alloy mainly because of their higher transformation temperatures. This shows an improved resistance against the plastic deformation in case of $30 \mathrm{Pd}$ and $35 \mathrm{Pd}$ alloys and is attributed to the increased volume fraction of the fine precipitates as shown in the XRD and SEM results. Although the formation of these precipitates improves the resistance against the plastic deformation, it also decreases 
Fig. 19 Backscattered SEM images of 10CRA sample with different magnifications [46]
Fig. 20 Backscattered SEM images of 40CRA sample with different magnifications [46]
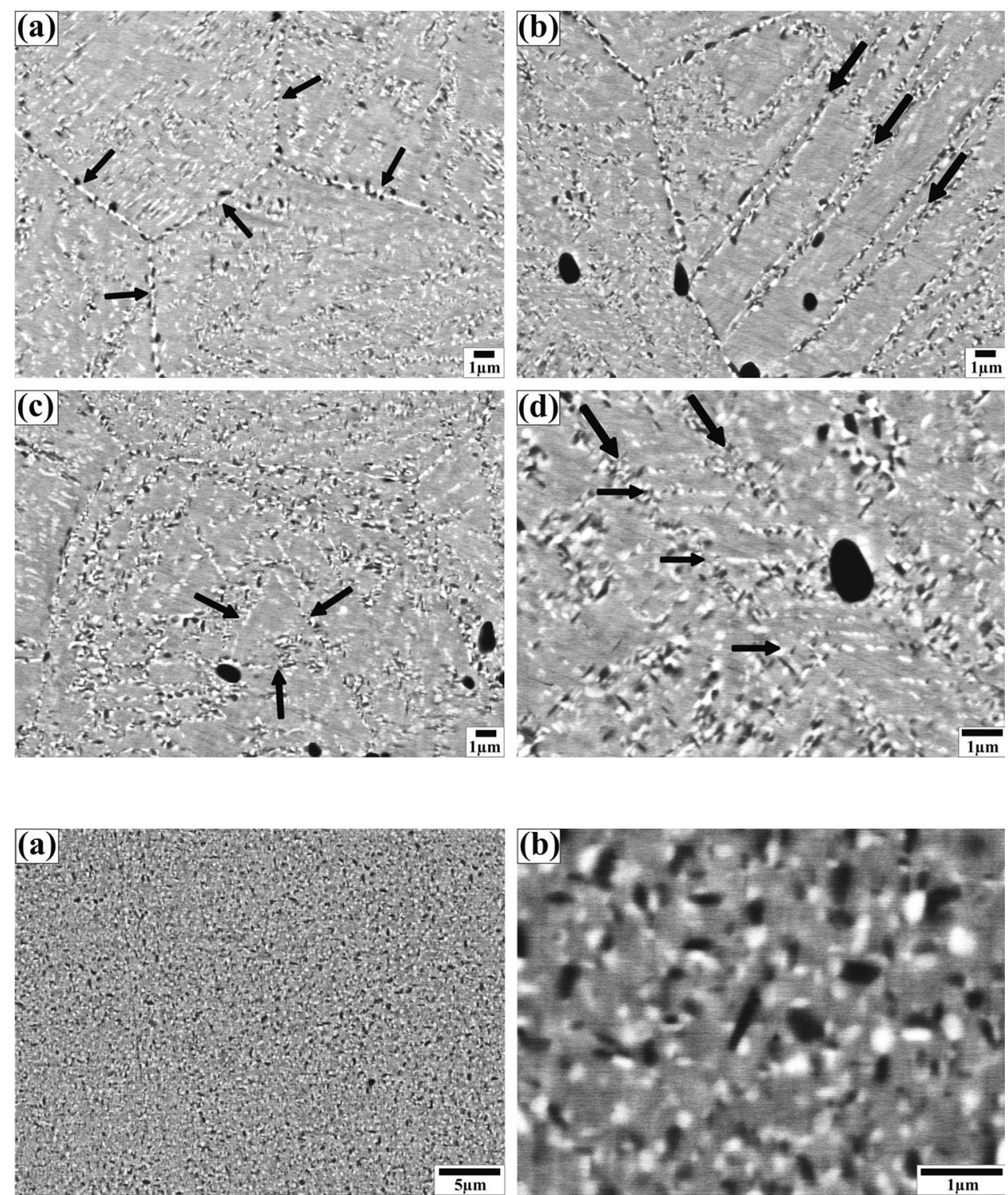

the volume fraction of B19 martensite matrix phase and obstructs the phase transformation. This causes a decrease in the overall recovery strain [47].

Annealing time is another important parameter to control the density and size of precipitates in TiNiPdCu alloys as shown in Fig. 24. By shortening the annealing time, the density and size of the precipitates decrease and the values of recovery strain increase. These results show that in case of precipitation-strengthened annealed TiNiPdCu-based high temperature shape memory alloys, the annealing time can be significantly helpful to achieve a better combination of high transformation temperatures, large recovery strains, and enough resistance against the plastic deformation [47].

It is concluded that by changing the density and size of precipitates, the combination of high transformation temperatures and large amount of recovery strain would be achievable while keeping the enough resistance against the plastic deformation [47].

\section{Aging Behavior of TiNiPdCu-Based Alloys}

Some research reports have indicated useful information about the aging behavior of TiNiPdCu. Lin et al. reported the precipitation of Ti-rich $\mathrm{Ti}_{2} \mathrm{Pd}$ - and $\mathrm{Cu}$-rich $\mathrm{Ti}(\mathrm{Cu}, \mathrm{Pd})_{2}$-type precipitates in a solution-treated and subsequently heat-treated $\mathrm{Ti}_{50} \mathrm{Ni}_{15} \mathrm{Pd}_{25} \mathrm{Cu}_{10}$ alloy within a temperature range of 723 $923 \mathrm{~K}$ for $21.6 \mathrm{ks}$ [36]. The authors used the term "annealing" instead of aging for the solution-treated and subsequently heattreated $\mathrm{Ti}_{50} \mathrm{Ni}_{15} \mathrm{Pd}_{25} \mathrm{Cu}_{10}$ alloy. In our papers we used the term "annealing" for the samples which were first cold rolled and subsequently heat treated at different temperatures and the 
Fig. 21 Room temperature $\mathrm{XRD}$ profiles of the a $25 \mathrm{Pd}$, b $30 \mathrm{Pd}$, and c $35 \mathrm{Pd}$ alloys heat treated at various temperatures between 673 and $1173 \mathrm{~K}$ [47]
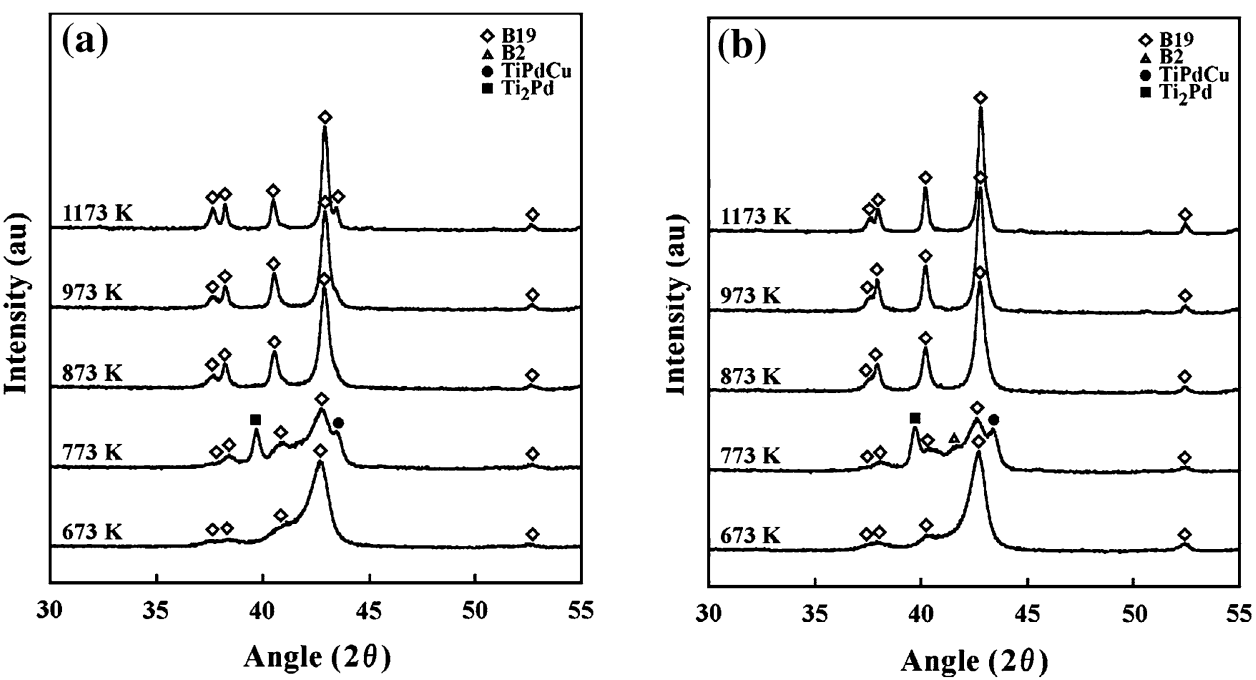

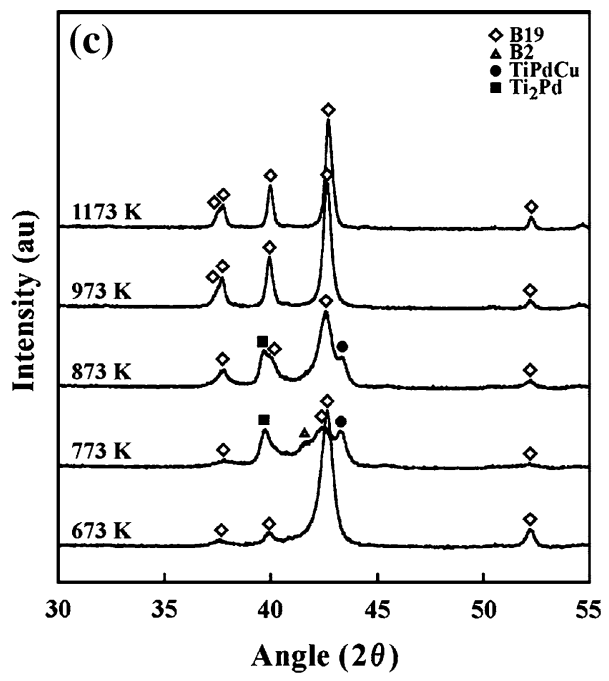

term "aging" for the samples which were first solution treated and then subsequently heat treated at different temperatures. In order to refer their research work, in this review paper, we used the same terminology as was used in their original paper. The density of precipitates is observed to be highest in $823 \mathrm{~K}$, lowest in $923 \mathrm{~K}$, and intermediate in $723 \mathrm{~K}$ annealed sample. The size of the precipitates increases with increasing annealing temperature. It is also claimed that the orientation relationships of precipitates and matrix can be identified as $[110]_{\mathrm{Ti}_{2} \mathrm{Pd}} / /$ $[110]_{\mathrm{B} 19}$ and $[100]_{\mathrm{Ti}(\mathrm{Cu}, \mathrm{Pd}) 2} / /[100]_{\mathrm{B} 19}$, respectively. The results also show that the formation of precipitates causes a significant depression in the martensitic transformation temperatures and transformation enthalpy $\left(\Delta H_{\mathrm{c}}\right)$ [36]. The depression in $\mathrm{M}_{\mathrm{s}}$ temperature and $\Delta H_{\mathrm{c}}$ values are attributed to the formation of $\mathrm{Ti}_{2} \mathrm{Pd}$ - and $\mathrm{Ti}(\mathrm{Cu}, \mathrm{Pd})_{2}$-type precipitates during the heat treatment of solution-treated $\mathrm{Ti}_{50} \mathrm{Ni}_{15} \mathrm{Pd}_{25} \mathrm{Cu}_{10}$ high temperature shape memory alloy. This research study gives the evidence of $\mathrm{Ti}_{2} \mathrm{Pd}$ - and $\mathrm{Ti}(\mathrm{Cu}, \mathrm{Pd})_{2}$-type precipitate formation but does not explain the precipitation mechanism of these precipitates in the heat-treated equiatomic $\mathrm{Ti}_{50} \mathrm{Ni}_{15} \mathrm{Pd}_{25} \mathrm{Cu}_{10}$ high temperature shape memory alloy [36].

Rehman et al. has reported the effects of aging temperature on the microstructure, hardness, phase transformation behavior, and shape memory properties of $\mathrm{Ti}_{50} \mathrm{Ni}_{15} \mathrm{Pd}_{25} \mathrm{Cu}_{10}$ high temperature shape memory alloy [48]. In this study the $\mathrm{Ti}_{50} \mathrm{Ni}_{15} \mathrm{Pd}_{25} \mathrm{Cu}_{10}$ alloy samples were solution treated at $900{ }^{\circ} \mathrm{C}$ for $1 \mathrm{~h}$. The solution-treated samples were aged at various temperatures from 350 to $750{ }^{\circ} \mathrm{C}$ for $3 \mathrm{~h}$. The detailed experimental procedure can be found in the original research report [48]. According to this study the aging temperatures can be divided into three categories, i.e., low aging temperature $\left(350{ }^{\circ} \mathrm{C}\right.$ and below), intermediate aging temperature $\left(400-600^{\circ} \mathrm{C}\right)$, and high aging temperature $\left(650{ }^{\circ} \mathrm{C}\right.$ and above) depending on the evolution of different properties with respect to the aging temperature. At low aging temperature, the properties, i.e., hardness and phase transformation temperatures, remain almost unaffected and are comparable with that of solution- 
Fig. 22 Backscattered-SEM images of the 25Pd, 30Pd, and 35Pd alloys heat treated at $773 \mathrm{~K}(\mathbf{a}-\mathbf{c})$ and $873 \mathrm{~K}(\mathbf{d}-$ f) $[47]$
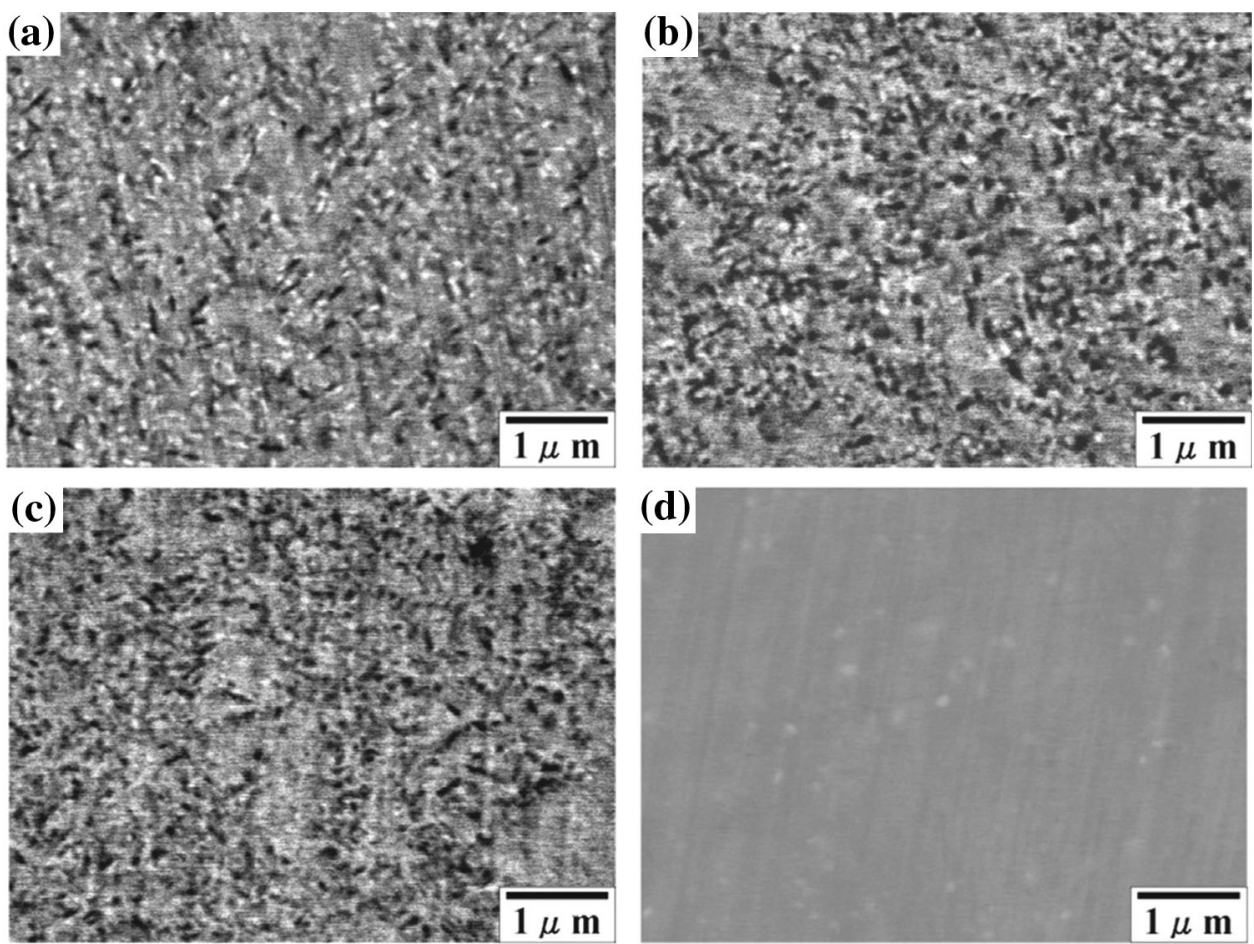

(e)

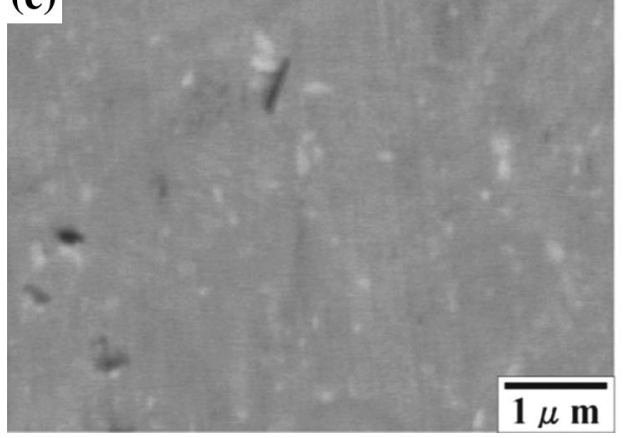

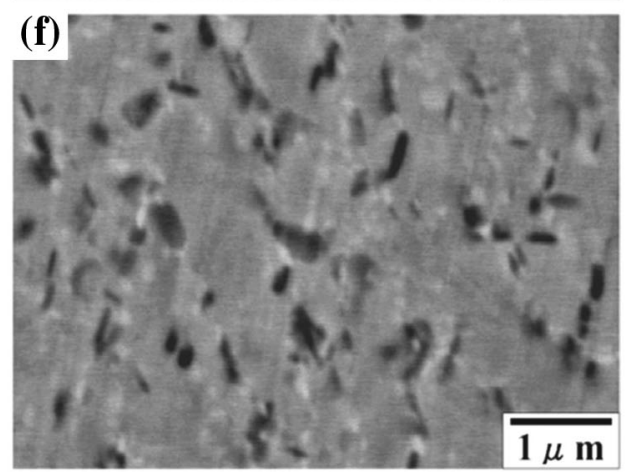

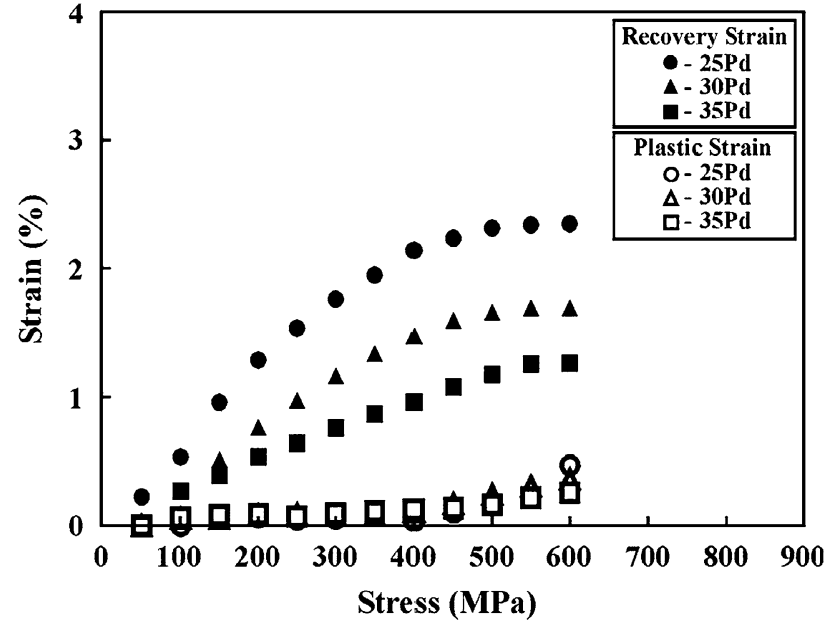

Fig. 23 Shape memory properties of the 25Pd, 30Pd, and 35Pd alloys heat treated at $773 \mathrm{~K}$ for $3.6 \mathrm{ks}$ [47] treated sample. At intermediate aging temperatures, $\mathrm{Ti}_{2} \mathrm{Pd}$ and $\mathrm{TiPdCu}$-type precipitates are formed. The formation of these precipitates increases the hardness and depresses the phase transformation temperatures. The study shows that the aging treatment at $550{ }^{\circ} \mathrm{C}$ results in the highest value of hardness and lowest martensitic transformation temperatures. Aging at $550{ }^{\circ} \mathrm{C}$ also decreases the irrecoverable strain which shows the improvement in dimensional stability. By aging the samples at temperatures higher than $550{ }^{\circ} \mathrm{C}$, the hardness decreases and the phase transformation temperatures increase again. The aging treatment at $700{ }^{\circ} \mathrm{C}$ produces the similar martensitic transformation temperatures and hardness values as can be seen in the case of solution-treated samples [48].

In another study, Rehman et al. studied the effects of thermomechanical training and precipitation strengthening on the shape memory behavior of TiNiPdCu-based alloys. In 
Fig. 24 Backscattered-SEM images of the 30Pd alloy heat treated at $773 \mathrm{~K}$ for a $1.8 \mathrm{ks}$, b $0.6 \mathrm{ks}$, c a TEM image of the $30 \mathrm{Pd}$ alloy heat treated at $773 \mathrm{~K}$ for $0.6 \mathrm{ks}$ and $\mathbf{d}$ shape memory properties of the 30Pd alloy heat treated at $773 \mathrm{~K}$ for $0.6,1.8$, and $3.6 \mathrm{ks}[47]$
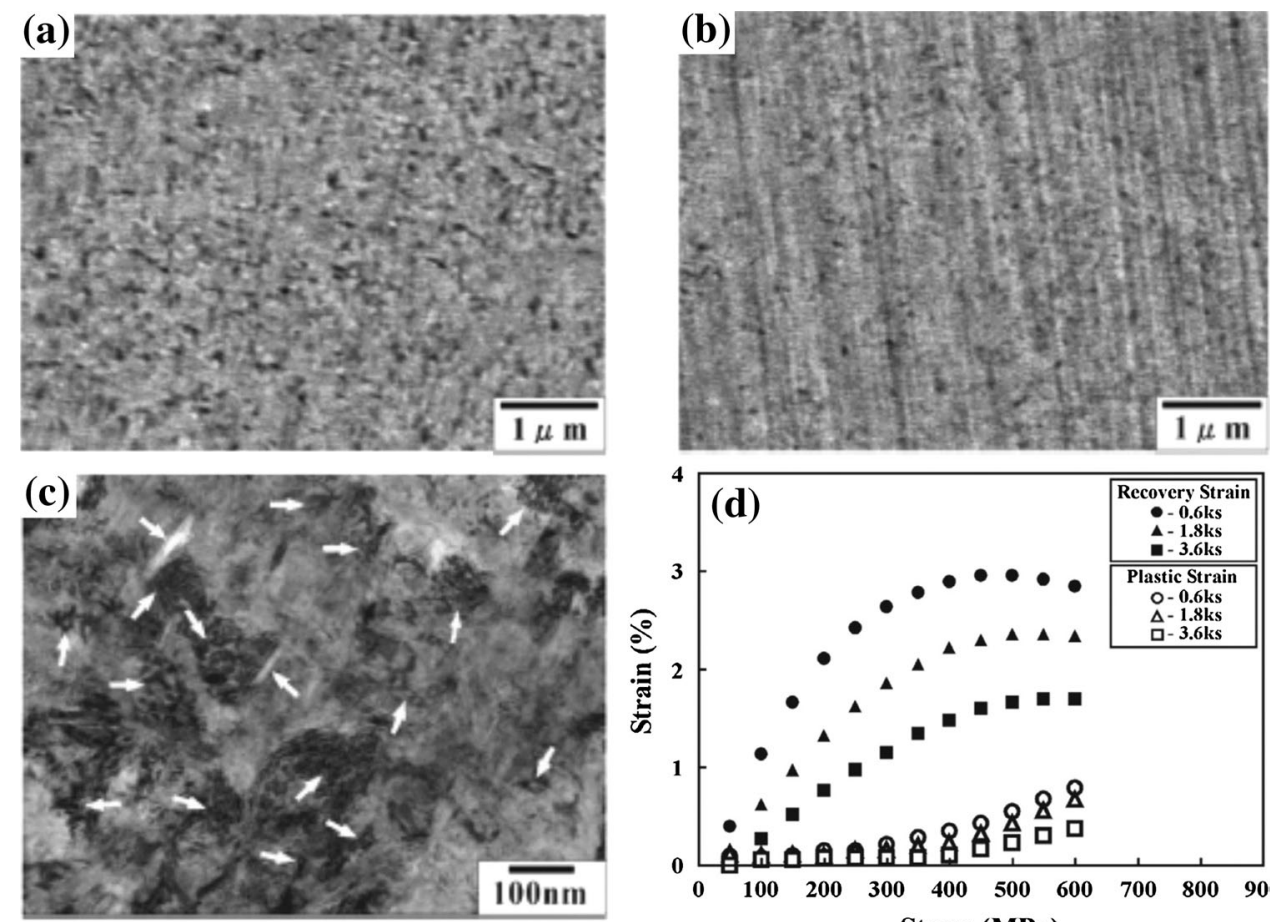

this study a $\mathrm{Ti}_{50} \mathrm{Ni}_{15} \mathrm{Pd}_{25} \mathrm{Cu}_{10}$ alloy was solution treated at $900{ }^{\circ} \mathrm{C}$ for $1 \mathrm{~h}$ and subsequently aged at $600{ }^{\circ} \mathrm{C}$ for $3 \mathrm{~h}$ in inert atmosphere. According to their claim, the aging treatment results in the formation of $\mathrm{TiPdCu}-$ and $\mathrm{Ti}_{2} \mathrm{Pd}$-type precipitates. They also claimed that the thermomechanical training of precipitate containing aged $\mathrm{Ti}_{50} \mathrm{Ni}_{15} \mathrm{Pd}_{25} \mathrm{Cu}_{10}$ alloy exhibits significantly improved cyclic stability [49].

The above-mentioned studies throw some light on the aging behavior of TiNiPdCu-based high temperature shape memory alloys and the resulting shape memory behavior. It is still thought that a detailed study of the precipitation behavior of aged alloys, aged microstructures, and their effectiveness, as compared to that of annealed TiNiPdCubased alloys, is needed in order to fully realize the potential of these alloys for real-time commercial applications.

\section{Concluding Remarks}

This review paper gives an overview of the TiNiPdCubased HTSMAs. This alloy system possesses significant potential to be used in the applications where high temperature shape memory effect can be utilized especially at those working temperatures where creep can become a serious problem. The purpose of this review paper is to summarize the important aspects of TiNiPdCu-based high temperature shape memory alloys which have already been published in the various research reports. By no means has this review covers every aspect of TiNiPdCu-based
HTSMAs and it only gives a brief view of the trend of the technology development and serves as guidance for many more potential engineering applications of this important high HTSMA system.

\section{References}

1. Kovarik L, Yang F, Garg A, Diercks D, Kaufman M, Noebe RD, Mills MJ (2010) Structural analysis of a new precipitate phase in high-temperature TiNiPt shape memory alloys. Acta Mater 58:4660-4673

2. Kim HY, Fukushima T, Buenconsejo PJS, Nam TH, Miyazaki S (2011) Martensitic transformation and shape memory properties of Ti-Ta-Sn high temperature shape memory alloys. Mater Sci Eng A 528:7238-7246

3. Delville R, Schryvers D, Zhang Z, James RD (2009) Transmission electron microscopy investigation of microstructures in lowhysteresis alloys with special lattice parameters. Scripta Mater 60:293-296

4. Monroe JA, Karaman I, Lagoudas DC, Bigelow G, Noebe RD, Padula S (2011) Determining recoverable and irrecoverable contributions to accumulated strain in a NiTiPd high-temperature shape memory alloy during thermomechanical cycling. Scripta Mater 65:123-126

5. Ma J, Karaman I, Noebe RD (2010) high temperature shape memory alloys. Int Mater Rev 55(5):257-314

6. Webster J (2006) High integrity adaptive SMA components for gas turbine applications. Proc SPIE 6171:61710F

7. Mabe JH, Calkins FT, Butler GW (2006) Boeing's variable geometry chevron, morphing, aerostructure for jet engine noise reduction. In: Proceedings of 47th Conference on Structures, structural dynamics, and materials, 2006-2142, AIAA, Newport 
8. Calkins F, Butler G, Mabe J (2006) Variable Geometry Chevrons for Jet Noise Reduction, AIAA-2006-2546, 12th AIAA/CEAS Aeroacoustics Conference, Cambridge

9. Padula II SA, Noebe RD, Bigelow GS, Culley D, Stevens M, Penney Gaydosh ND, Quackenbush T, Carpenter B (2007) Development of a HTSMA-actuated surge control rod for hightemperature turbomachinery applications. In: Proceedings of 48th Conference on 'Structures, structural dynamics, and materials', 2007-2196, AIAA, Honolulu

10. McDonald Schetky L (1991) Shape memory alloy applications in space systems. Mater Des 12:29-32

11. Stoeckel D (1990) Shape memory actuators for automotive applications. Mater Des 11(6):302-307

12. Gore JG, Chandresekaran L, Bowles AR, Maylin MG, Forsyth D, Byers M (2008) High-temperature shape-memory alloy actuators through mechanical treatments for an oil and gas down-hole valve. Proc SPIE 6930:6930-7027

13. Gore J, Bowles A, Maylin M, Chandrasekaran L, Forsyth D, Buyers M (2008) Industrial and Commercial Applications of Smart Structures Technologies. Proc SPIE 6930:69300R

14. Liu Y, Kohl M, Okutsu K, Miyazaki S (2004) A TiNiPd thin film microvalve for high temperature application. Mater Sci Eng A A378:205

15. Huff MA, Bernard WL, Lisy FJ, Prince TS (2003) Method and sensor for detecting strain using shape memory alloys. US Patent 6622558

16. MIGA Motor Company. http://www.migamotors.com/Products. html

17. Miyazaki S, Otsuka K (1989) Development of shape memory alloys. ISIJ Int 29:353-377

18. Eckelmeyer E (1976) The effect of alloying on the shape memory phenomenon in nitinol. Scr Metall 10:667

19. Lo Y, Wu S (1991) Compositional dependence of martensitic transformation sequence in $\mathrm{Ti}_{50} \mathrm{Ni}_{50}-x \mathrm{Pd} x$ alloys with $\mathrm{X} \leq$ 15at\%. Scr Metall Mater 27:1097

20. Angst D, Thoma P, Kao M (1995) The effect of hafnium content on the transformation temperatures of $\mathrm{Ni}_{49} \mathrm{Ti}{ }_{51-\mathrm{x}} \mathrm{Hf}_{\mathrm{x}}$ shape memory alloys. J Phys IV C8:747

21. Olier P, Brachet J, Bechade J, Foucher C, Guenin G (1995) Investigation of transformation temperatures, microstructure and shape memory properties of NiTi, NiTiZr and NiTiHf alloys. J Phys IV C8:741

22. Donkersloot HC, Vucht JHNVJ (1970) Martensitic transformations in gold-titanium, palladium-titanium and platinum-titanium alloys near the equiatomic composition. Less Common Met 20:83-91

23. Thoma PE, Boehm JJ (1999) Effect of composition on the amount of second phase and transformation temperatures of $\mathrm{Ni}_{\mathrm{x}} \mathrm{Ti}_{90-\mathrm{x}}$ $\mathrm{Hf}_{10}$ shape memory alloys. Mater Sci Eng 273-275:385

24. Lo YC, Wu SK, Wayman CM (1990) Transformation heat as a function of ternary $\mathrm{Pd}$ additions in $\mathrm{Ti}_{50} \mathrm{Ni}_{50-\mathrm{z}} \mathrm{Pd}_{\mathrm{z}}$ alloys with x:20 50 at.\%. Scripta Metall Mater 24:1571

25. Kim HY, Jinguu T, Nam TH, Miyazaki S (2011) Cold workability and shape memory properties of novel Ti-Ni-Hf-Nb hightemperature shape memory alloys. Scr Mater 65(9):846-849

26. Golberg D, Xu Y, Murakami Y, Morito S, Otsuka K, Ueki T, Horikawa $\mathrm{H}$ (1995) Characteristics of $\mathrm{Ti}_{50} \mathrm{Pd}_{30} \mathrm{Ni}_{20}$ high-temperature shape memory alloy. Intermetallics 3:35-46

27. Xu Y, Shimizu S, Suzuki Y, Otsuka K, Ueki T, Mitose K (1997) Recovery and recrystallization processes in TiPdNi high-temperature shape memory alloys. Acta Mater 45(4):1503-1511

28. Atli KC, Karaman I, Noebe RD, Maier HJ (2011) Comparative analysis of the effects of severe plastic deformation and thermomechanical training on the functional stability of $\mathrm{Ti}_{50.5-}$ $\mathrm{Ni}_{24.5} \mathrm{Pd}_{25}$ high-temperature shape memory alloy. Scr Mater 64(4):315-318
29. Bigelow GS, Padula SA, Grag A, Gaydosh D, Noebe RD (2010) Characterization of ternary NiTiPd high-temperature shapememory alloys under load-biased thermal cycling. Metall Mater Trans A 41(12):3065

30. Atli KC, Karaman I, Noebe RD (2011) Work output of the twoway shape memory effect in $\mathrm{Ti}_{50.5} \mathrm{Ni}_{24.5} \mathrm{Pd}_{25}$ high-temperature shape memory alloy. Scr Mater 65(10):903-906

31. Parikshith KK, Dimitris C, Lagoudas C (2010) Experimental and microstructural characterization of simultaneous creep, plasticity and phase transformation in $\mathrm{Ti}_{50} \mathrm{Pd}_{40} \mathrm{Ni}_{10}$ high-temperature shape memory alloy. Acta Mater 58(5):1618-1628

32. Parikshith KK, Desai U, Monroe James A, Lagoudas C, Karaman I, Bigelow G, Noebe RD (2011) Experimental investigation of simultaneous creep, plasticity and transformation of $\mathrm{Ti}_{50.5} \mathrm{Pd}_{30-}$ $\mathrm{Ni}_{19.5}$ high temperature shape memory alloy during cyclic actuation. Mater Sci Eng A 530:117-127

33. Khan IM, Kim HY, Nam TH, Miyazaki S (2013) Effect of Cu addition on the high temperature shape memory properties of $\mathrm{Ti}_{50} \mathrm{Ni}_{25} \mathrm{Pd}_{25}$ alloy. J Alloy Compd 577S:S383-S387

34. Khan MI, Kim HY, Nam TH, Miyazaki S (2012) Formation of nanoscaled precipitates and their effects on the high-temperature shape-memory characteristics of a $\mathrm{Ti}_{50} \mathrm{Ni}_{15} \mathrm{Pd}_{25} \mathrm{Cu}_{10}$ alloy. Acta Mater 60(16):5900-5913

35. Khan MI, Kim HY, Namigata Y, Nam TH, Miyazaki S (2013) Combined effects of work hardening and precipitation strengthening on the cyclic stability of TiNiPdCu-based high-temperature shape memory alloys. Acta Mater 61(13):4797-4810

36. Lin KN, Wu SK, Wu LM (2009) Martensitic Transformation of $\mathrm{Ti}_{50} \mathrm{Ni}_{25-\mathrm{X}} \mathrm{Pd}_{25-\mathrm{Y}} \mathrm{Cu}_{\mathrm{X}+\mathrm{Y}}$ Quaternary Shape Memory Alloys with X, Y $5<10$ at\%. Mater Trans 50(10):2384-2390

37. Rehman SU, Khan M, Khan AN, Jaffery SHI, Ali L, Mubashar A. Improvement in the Mechanical Properties of High Temperature Shape Memory Alloy $\left(\mathrm{Ti}_{50} \mathrm{Ni}_{25} \mathrm{Pd}_{25}\right)$ by Copper Addition. Hindawi Publishing Corporation, Adv in Mater Sci Eng, Volume 2015, Article ID 434923

38. Delville R, Kasinathan S, Zhang Z, Humbeeck JV, James DR, Schryvers D (2010) Transmission electron microscopy study of phase compatibility in low hysteresis shape memory alloys. Phil Mag 90(1-4):177-195

39. Kockar B, Karaman I, Kim JI, Chumlyakov YI, Sharp J, Yu CJ (2008) Thermomechanical cyclic response of an ultrafine-grained NiTi shape memory alloy. Acta Mater 56(14):3630-3646

40. Kockar B, Atli KC, Ma J, Haouaoui M, Karaman I, Nagasako M, Kainuma R (2010) Role of severe plastic deformation on the cyclic reversibility of a $\mathrm{Ti}_{50.3} \mathrm{Ni}_{33.7} \mathrm{Pd}_{16}$ high temperature shape memory alloy. Acta Mater 58(19):6411-6420

41. He SM, Dijk NHV, Schut H, Peekstok ER, Zwaag SV (2010) Thermally activated precipitation at deformation-induced defects in $\mathrm{Fe}-\mathrm{Cu}$ and $\mathrm{Fe}-\mathrm{Cu}-\mathrm{B}-\mathrm{N}$ alloys studied by positron annihilation spectroscopy. Phy Rev B 81:094103

42. Semboshi S, Orimo SI, Suda H, Gao W, Sugawara A (2011) Aging of copper-titanium dilute alloys in hydrogen atmosphere: influence of prior-deformation on strength and electrical conductivity. Mater Trans 52(12):2137-2142

43. Lin KN, Wu SK, Wu LM (2009) Martensitic transformation of cold-rolled and annealed $\mathrm{Ti}_{50} \mathrm{Ni}_{40} \mathrm{Cu}_{10}$ shape memory alloy. Mater Trans 50(11):2637-2642

44. Filip P, Mazanec K (2001) On precipitation kinetics in TiNi shape memory alloys. Scr Mater 45:701-707

45. Nishida M, Wayman CM, Chiba A (1988) Electron microscopy studies of martensitic transformation of an aged Ti-51 at. \% Ni shape memory alloy. Metallography 21:275-291

46. Khan MI, Kim HY, Khalid FA, Miyazaki S (2014) Effect of cold rolling ratio on the nanoscale precipitation behavior of $\mathrm{TiNiPdCu}$ based high temperature shape memory alloys. J Alloys Comp 599:212-218 
47. Imahashi M, Khan MI, Kim HY, Miyazaki S (2014) The effect of $\mathrm{Pd}$ content on microstructure and shape-memory properties of TiNiPdCu alloys. Mater Sci Eng A 602:19-24

48. Rehman SU, Khan M, Khan AN, Ali L, Sabah Z, Waseem M, Ali L, Jaffery SHI (2014) Transformation behavior and shape memory properties of $\mathrm{Ti}_{50} \mathrm{Ni}_{15} \mathrm{Pd}_{25} \mathrm{Cu}_{10}$ high temperature shape memory alloy at various aging temperatures. Mater Sci Eng A 619:171-179
49. Rehman SU, Khan M, Khan AN, Khan MI, Ali L, Jaffery SHI (2014) Effect of precipitation hardening and thermomechanical training on microstructure and shape memory properties of $\mathrm{Ti}_{50} \mathrm{Ni}_{15} \mathrm{Pd}_{25} \mathrm{Cu}_{10}$ high temperature shape memory alloys. J Alloys Comp 616:275-283 